\title{
Developmental Pathogenicity of 4-Repeat Human Tau Is Lost with the P301L Mutation in Genetically Matched Tau-Transgenic Mice
}

\author{
- Julia E. Gamache, ${ }^{1,4}$ Lisa Kemper, ${ }^{1,4}$ Elizabeth Steuer, ${ }^{1,4}$ Kailee Leinonen-Wright, ${ }^{1,4}$ Jessica M. Choquette, ${ }^{1,4}$ \\ Chris Hlynialuk, ${ }^{1,4}$ Kellie Benzow, ${ }^{2,4}$ Keith A. Vossel, ${ }^{1,4}$ Weiming Xia, ${ }^{3}$ Michael D. Koob, ${ }^{2,4}$ and Karen H. Ashe ${ }^{1,4}$ \\ ${ }^{1} \mathrm{~N}$. Bud Grossman Center for Memory Research and Care, Department of Neurology, ${ }^{2}$ Department of Laboratory Medicine and Pathology, University of \\ Minnesota, Minneapolis, Minnesota 55455, ${ }^{3}$ Department of Pharmacology and Experimental Therapeutics, Boston University School of Medicine, Boston, \\ Massachusetts 02118, and Bedford Veterans Administration Medical Center, Bedford, Massachusetts 01730, and ${ }^{4}$ Wallin Medical Biosciences Building, \\ Minneapolis, Minnesota 55455
}

Tau is a microtubule-associated protein that becomes dysregulated in a group of neurodegenerative diseases called tauopathies. Differential tau isoforms, expression levels, promoters, and disruption of endogenous genes in transgenic mouse models of tauopathy make it difficult to draw definitive conclusions about the biological role of tau in these models. We addressed this shortcoming by characterizing the molecular and cognitive phenotypes associated with the pathogenic P301L tau mutation (rT2 mice) in relation to a genetically matched transgenic mouse overexpressing nonmutant (NM) 4-repeat (4R) human tau (rT1 mice). Both male and female mice were included in this study. Unexpectedly, we found that 4R NM human tau (hTau) exhibited abnormal dynamics in young mice that were lost with the P301L mutation, including elevated protein stability and hyperphosphorylation, which were associated with cognitive impairment in 5-month-old rT1 mice. Hyperphosphorylation of NM hTau was observed as early as 4 weeks of age, and transgene suppression for the first 4 or 12 weeks of life prevented abnormal molecular and cognitive phenotypes in rT1, demonstrating that NM hTau pathogenicity is specific to postnatal development. We also show that NM hTau exhibits stronger binding to microtubules than P301L hTau, and is associated with mitochondrial abnormalities. Overall, our genetically matched mice have revealed that $4 \mathrm{R} \mathrm{NM} \mathrm{hTau} \mathrm{overexpression} \mathrm{is}$ pathogenic in a manner distinct from classical aging-related tauopathy, underlining the importance of assaying the effects of transgenic disease-related proteins at appropriate stages in life.

Key words: mouse model; tau; tauopathy; transgenesis

\section{Significance Statement}

Due to differences in creation of transgenic lines, the pathological properties of the P301L mutation confers to the tau protein in vivo have remained elusive, perhaps contributing to the lack of disease-modifying therapies for tauopathies. In an attempt to characterize P301L-specific effects on tau biology and cognition in novel genetically matched transgenic mouse models, we surprisingly found that nonmutant human tau has development-specific pathogenic properties of its own. Our findings indicate that overexpression of 4-repeat human tau during postnatal development is associated with excessive microtubule binding, which may disrupt important cellular processes, such as mitochondrial dynamics, leading to elevated stability and hyperphosphorylation of tau, and eventual cognitive impairments.

\section{Introduction}

Tau is the main axonal microtubule (MT)-associated protein of the mammalian central nervous system. Although tau is principally found in neuronal axons where it functions in MT assembly
(Weingarten et al., 1975) and MT transport (Dixit et al., 2008), it has other "atypical" functions in different regions in an isoformdependent manner (Liu and Götz, 2013), such as receptor anchoring (Ittner et al., 2010) and DNA protection (Benhelli- 
Mokrani et al., 2018). Perhaps because of the complex and multifunctional role of tau in neuron biology, tau dysfunction in a family of neurodegenerative diseases called tauopathies can result in a wide spectrum of clinical and neuropathological phenotypes.

The mechanisms underlying tau pathogenicity remain unclear, in part due to extreme variability in phenotypes of tauopathy mouse models. The P301L mutation is frequently used to model human disease because it is the most common MAPT mutation (AD and FTD mutation database). Although in vitro studies indicate that this mutation confers pathogenic properties to the tau protein, such as reduced MT binding (Hong et al., 1998), this idea is inconsistently replicated in mouse models. Transgenic mice harboring the P301L mutation exhibit diverse phenotypes, such as severe early neuropathology (Santacruz et al., 2005), late-onset tauopathy (de Calignon et al., 2012), progressive motor impairments (Lewis et al., 2000), mild or absent phenotypes (Kimura et al., 2010; Gilley et al., 2012), or even improvements in cognition (Boekhoorn et al., 2006).

Mouse models expressing nonmutant (NM) human tau should be used as controls for P301L models; however, NM tau mouse models also have a range of phenotypes, including mild phenotypes (Götz et al., 1995; Brion et al., 1999), developmental neuropathology (Terwel et al., 2005; Orr et al., 2012), progressive synaptic and cognitive impairments (Polydoro et al., 2009), neurodegeneration (Andorfer et al., 2005), progressive tauopathy (Ishihara et al., 1999, 2001; Adams et al., 2009), glial pathology (Higuchi et al., 2002; Forman et al., 2005), and axonopathy associated with motor deficits (Spittaels et al., 1999; Probst et al., 2000; Terwel et al., 2005).

Variability in tauopathy mouse models can be attributed to differential tau isoforms, expression levels, promoters, and disruption of endogenous genes (Goodwin et al., 2019). We recently found that, in a popular tauopathy mouse model, rTg4510, two transgene insertion-deletion (INDEL) mutations disrupt genes important for brain function, calling into question the precise role of tau in that phenotype (Gamache et al., 2019). If confounding variables, such as those associated with random genome disruption, are not specifically accounted for, it is difficult to draw conclusions about the biological role of tau in tauopathies.

In this study, our goal was to characterize phenotypes associated with the P301L mutation by systematically comparing a novel P301L mouse model to a genetically matched NM mouse line with the same human tau (hTau) isoform, expression pattern, and transgene insertion sites in the genome. These lines harbor a single copy of a "responder" human tau transgene in the same nondisruptive genomic locus. To activate hTau expression, they are crossed to the same "activator" tTA line used in our previous publication, which has a transgene INDEL mutation that disrupts several forebrain genes and causes dentate gyrus degeneration (Han et al., 2012; Gamache et al., 2019). Unfortunately, these studies began before we were aware of the genomic disruption in the tTA line; however, we control for this confound because the lines are genetically identical, except for the P301L mutation.

Unexpectedly, we found that the NM mouse line we intended to use as a control exhibited a robust and early phenotype, which

assistance with the human tau ELISAs; Dr. Pascal Verdier-Pinard for advising us in the MT experiments; and Samuel Peters for his technical assistance in making neuronal cultures.

The authors declare no competing financial interests.

Correspondence should be addressed to Karen H. Ashe at hsia0005@umn.edu.

https://doi.org/10.1523/JNEUROSCI.1256-19.2019

Copyright $(2020$ the authors
Table 1. Primer sequences used for relative RT-qPCR

\begin{tabular}{lll}
\hline & Primers \\
\cline { 2 - 3 } Target & Forward & Reverse \\
\hline hTau & 5'- CTACACCATGCACCAAGACC-3' & 5'- TGCTTTTACTGACCATGCGA-3' \\
Hprt & 5' - GCTGGTGAAAAGGACCTCT-3' $^{\prime}$ & 5' - CCACAGGACTAGAACACCTGCTA-3' \\
\hline
\end{tabular}

was absent in the P301L line. Our findings indicate that overexpression of the $0 \mathrm{~N} 4 \mathrm{R}$ isoform of NM hTau is pathogenic during postnatal development, in a manner distinct from classical agingrelated tauopathy. We show that developmental toxicity of NM hTau is associated with strong MT binding, which we hypothesize is a pathological trigger that leads to a disruption of cellular processes and eventual cognitive dysfunction.

\section{Materials and Methods}

Animals. An ES cell line generated in the M.D.K. laboratory was used for this work (Gamache et al., 2019). A construct was generated that was essentially identical to the construct used to generate Tg4510 but incorporated an Flp-In promoter cassette (PGK promoter-ATG-FRT), and 6 $\mu \mathrm{g}$ of this construct and $0.5 \mu \mathrm{g}$ of pCAGGS-FlpE (Gene Bridges, catalog \#A201) were transfected into the V6.5Col1a\#15 ES cell line. Hygromycin selection at $140 \mu \mathrm{g} / \mathrm{ml}$ was added days 2-6, and Hygro-resistant ES clones were picked on day 7. DNA was analyzed for 5' (5ArmCollA assay primer + tetracycline response element [TRE] start reverse) and $3^{\prime}$ (AMP R reverse + Hygro connection) junctions, internal Tau (TAU assay $\mathrm{F}$ and $\mathrm{R}$ ), and multiple integration assay (AMP R Reverse + TRE start R) by PCR. Clones that passed all assays were expanded and karyotyped, and $\mathrm{T} 1(\mathrm{NM})$ and $\mathrm{T} 2(\mathrm{P} 301 \mathrm{~L})$ responder mice were generated by injection into blastocysts. These mice were back-crossed 5 times to FVB before generating the rT1 and rT2 lines.

ES cell assay primer sequences are as follows: 5 ArmCollA pcr assay 5'-CAGGTGCACAGCATTGCGGACATG-3'; TRE start reverse 5'-AT TGCTCCAGGCGATCTGAC-3'; Amp R reverse 5'-GGAATAAGGGC GACACGGAA-3'; Hygro connection 5'-ATCCACGCCCTCCTACAT CGAA-3'; Tau assay forward 5'-GTTCGAAGTGATGGAAGATCACG3'; and Tau assay reverse 5'-TTGGGTGGAGTACGGACCA-3'. PCR probe primers are as follows: Amp forward $5^{\prime}$-CCTCCATCCAGTC TATTAATT-3'; and Amp reverse 5'-TCCTTGAGAGTTTTCGCC CCG-3'.

A human tau plasmid was used to generate $\mathrm{T} 1$ and $\mathrm{T} 2$ responders, which harbor a 0 N4R human tau cDNA transgene flanked by noncoding regions of the murine Prion protein gene and regulated by a TRE. Activator mice harbor a tetracycline transactivator (tTA) transgene under the control of the CaMKII $\alpha$-tTA (tTA) promoter to drive expression specifically in forebrain excitatory neurons (Mayford et al., 1996). Human tau expression is activated in bigenic Tau ${ }^{+/-} \mathrm{tTA}^{+/-} \mathrm{rT} 1$ and $\mathrm{rT} 2$ progeny of an activator-responder cross. Responder $\mathrm{T} 1$ and $\mathrm{T} 2$ mice were maintained on an FVB/N background, whereas activator mice were maintained on a $129 \mathrm{~S} 6$ background. Littermates with $\mathrm{Tau}^{+/-} \mathrm{tTA}^{-1-}$, $\mathrm{Tau}^{-1-} \mathrm{tTA}^{+/-}$, and $\mathrm{Tau}^{-1-} \mathrm{tTA}^{-1-}$ genotypes were used as controls. Both male and female mice were used and combined in statistical analyses after demonstrating the absence of significant gender effects $(p>$ $0.05)$. All animal breeding was conducted conservatively assuming 8 pups per litter based on accumulated data from the K.H.A. laboratory colony. All experiments with animals described in this study were conducted in full accordance with the American Association for the Accreditation of Laboratory Animal Care and the Institutional Animal Care and Use Committee at the University of Minnesota.

$q R T-P C R$. mRNA expression levels of hTau were quantified relative to a reference gene, Hprt (Table 1). Total cellular RNA was extracted from homogenized forebrain tissue using RNeasy Lipid Tissue Kit (QIAGEN) according to the manufacturer's instructions. RNA samples were treated with DNaseI (New England Biolabs) to digest contaminating DNA, and subjected to cDNA synthesis using the iScript cDNA synthesis kit (Invitrogen) according to the manufacturer's instructions. PCRs were set up in a $20 \mu \mathrm{l}$ volume in 96 -well plates, with 3 replicates per sample. Roche 
Table 2. PCR cycling conditions for relative $\mathrm{QRT}-\mathrm{PCR}$

\begin{tabular}{lll}
\hline No. of cycles & Temperature $\left({ }^{\circ} \mathrm{C}\right)$ & Time $(\min : s)$ \\
\hline 1 & 95 & $10: 00$ \\
32 & 95 & $00: 10$ \\
& 55 & $00: 10$ \\
& 72 & $00: 10$ \\
\hline
\end{tabular}

SYBR Green PCR master mix was used, and reactions were run in the Roche LightCycler 480 instrument (Table 2). A final melting curve confirmed that single amplicons were present for each variant and reference reactions, and a basic relative quantification was performed using the $\Delta \Delta \mathrm{C}_{\mathrm{T}}$ method (LightCycler 480 Software release 1.5.0 SP3). All data were normalized to a positive calibrator sample used in each experiment.

Protein extraction from brain tissue in RIPA buffer. Soluble and insoluble protein was extracted from mouse forebrain hemisphere tissue in RIPA buffer (50 mm Tris- $\mathrm{HCl}, 150 \mathrm{~mm} \mathrm{NaCl}, 1 \mathrm{~mm}$ EDTA, 0.5\% Triton X-100, $1 \%$ sodium deoxycholate, $0.3 \%$ SDS, 0.1 mm PMSF, 0.2 mm 1,10phenoanthroline monohydrate, Phosphatase Inhibitor Cocktail A (Sigma-Aldrich), Protease Inhibitor Cocktail (Sigma-Aldrich), and Phosphatase Inhibitor Cocktail 2 (Sigma-Aldrich) by drawing up and expulsing tissue through $1 \mathrm{ml}$ Monoject syringes (Covidien) first without and then with 20G BD PrecisionGlide needles. Homogenates were nutated for $1 \mathrm{~h}$ at $4^{\circ} \mathrm{C}$ and then centrifuged at 13,000 rpm for $90 \mathrm{~min}$ at $4^{\circ} \mathrm{C}$, and the supernatant was collected.

Protein extraction from brain tissue in TBS buffer. Soluble protein was extracted from mouse left forebrain hemispheres in TBS buffer $(25 \mathrm{~mm}$ Tris-HCl, pH 7.4, $140 \mathrm{~mm} \mathrm{NaCl}, 3 \mathrm{~mm} \mathrm{KCl}$ ) using a Dounce Homogenizer (PolyScience) at setting 10 for 25 strokes. A series of protease inhibitors were added to buffer within $1 \mathrm{~h}$ of use at the following final concentrations: $0.1 \mathrm{~mm}$ PMSF, $0.2 \mathrm{~mm}$ 1,10-phenoanthroline monohydrate, Phosphatase Inhibitor Cocktail A (Sigma-Aldrich), Protease Inhibitor Cocktail (Sigma-Aldrich), and Phosphatase Inhibitor Cocktail 2 (Sigma-Aldrich). After homogenization, samples were centrifuged at $15.6 \times g$ for $90 \mathrm{~min}$ at $4^{\circ} \mathrm{C}$. Supernatants were collected and diluted appropriately for ELISA.

Subcellular fractionation of brain tissue. Mouse right forebrain hemispheres were biochemically fractionated into cytosolic and light membrane (GAPDH-enriched [G-E]), presynaptic (synaptophysin-enriched $[\mathrm{S}-\mathrm{E}]$ ), and postsynaptic (PSD-95-enriched [P-E]) fractions using a modified version of a previously published protocol (Wang et al., 2013). Briefly, to obtain the G-E fraction, tissue was gently homogenized in sucrose buffer (0.32 m sucrose, 25 mm HEPES, pH 7.4) using a Dounce Homogenizer (PolyScience) at setting 1 for 12 strokes. Homogenates were centrifuged at $3000 \times g$ for $5 \mathrm{~min}$ at $4^{\circ} \mathrm{C}$. The supernatant was then centrifuged at $10,000 \times g$ for $12 \mathrm{~min}$ at $4^{\circ} \mathrm{C}$, and the resulting supernatant was collected. To obtain the S-E fraction, pellets were washed in sucrose buffer and then resuspended in HBS (25 mM HEPES, $150 \mathrm{~mm} \mathrm{NaCl}, \mathrm{pH}$ 7.4); $80 \%$ Triton X-100 (Sigma-Aldrich) was added to the suspension for a final concentration of $2 \%$. Samples were then incubated on ice for 30 min, centrifuged at $10,000 \times g$ for $20 \mathrm{~min}$ at $4^{\circ} \mathrm{C}$, and the resulting supernatant was collected. To obtain the P-E fraction, pellets were resuspended in PBS (0.01 м phosphate buffer, $0.0027 \mathrm{M} \mathrm{KCl,} 0.137 \mathrm{M} \mathrm{NaCl}, \mathrm{pH}$ 7.4). A series of protease inhibitors were added to all buffers within $1 \mathrm{~h}$ of use at the following final concentrations: $0.1 \mathrm{mM}$ PMSF, $0.2 \mathrm{~mm} \mathrm{1,10-}$ phenoanthroline monohydrate, Phosphatase Inhibitor Cocktail A (Sigma-Aldrich), Protease Inhibitor Cocktail (Sigma-Aldrich), and Phosphatase Inhibitor Cocktail 2 (Sigma-Aldrich).

Phosphatase treatment of brain extracts. RIPA extracts (see above) were treated with calf intestinal alkaline phosphatase (CIP, New England Biolabs), and samples were resuspended in $10 \mu \mathrm{l} \mathrm{CIP}$ buffer $(100 \mathrm{~mm} \mathrm{NaCl}$, $50 \mathrm{~mm}$ Tris- $\mathrm{HCl}, 10 \mathrm{~mm} \mathrm{MgCl}, 1 \mathrm{~mm}$ DTT, EDTA-free protease inhibitor cocktail, $\mathrm{pH}$ 7.9) per $1 \mu \mathrm{g}$ protein. One unit CIP per microgram of protein was added to the samples before incubation at $37^{\circ} \mathrm{C}$ for $30 \mathrm{~min}$. Samples were then concentrated using $0.5 \mathrm{ml} 10 \mathrm{~K}$ Amicon Ultra centrifugal filters (Millipore, UFC501096).

Isolation of MTs and MT-associated proteins (MAPs). MTs and MAPs were isolated using a previously published protocol (Miller et al., 2010), which was modified from two original publications (Kuznetsov et al., 1981; Vallee, 1982). Mouse forebrains were flash frozen in liquid nitrogen and crushed into a powder using a mortar and pestle. The powder was resuspended in $1.5 \times$ volume of MES/glutamate buffer $(0.1 \mathrm{M} \mathrm{pH} 6.8$ 2-(N-morpholino)ethanesulfonic acid, $0.5 \mathrm{~mm} \mathrm{MgCl}_{2}, 1 \mathrm{~mm}$ EGTA, $1 \mathrm{~m}$ glutamate) containing $1 \mathrm{~mm}$ DTT. The suspensions were sonicated 5 times for $10 \mathrm{~s}$ with $30 \mathrm{~s}$ rest intervals on ice (sonicator amplitude 20\%, 1 short burst per second done manually in continuous mode) (Thermo Fisher Scientific, 150E Digital Sonic Dismembrator, with model 4C15 cell disruptor). Samples were ultracentrifuged at $30,000 \times g$ at $4^{\circ} \mathrm{C}$ for 15 $\min$, and then supernatants were ultracentrifuged at $120,000 \times g$ at $4^{\circ} \mathrm{C}$ for $1 \mathrm{~h}$ (Beckman Coulter, Optima L-80 XP Ultracentrifuge with Type $70.1 \mathrm{Ti}$ Fixed-Angle Titanium rotor and $4 \mathrm{ml}$ thick-walled polycarbonate tubes); $20 \mu \mathrm{M}$ Taxol (paclitaxel, ApexBio, \#A4393) and $1 \mathrm{~mm}$ GTP were added to the clarified supernatants, which were then incubated at $37^{\circ} \mathrm{C}$ for $30 \mathrm{~min}$. Samples were gently layered onto a sucrose cushion (MES/ glutamate buffer containing 20\% sucrose) and ultracentrifuged at $30,000 \times g$ at $37^{\circ} \mathrm{C}$ for $30 \mathrm{~min}$. The supernatants were then collected as the cytosolic fraction while MT/MAP pellets were resuspended in $50 \mu \mathrm{l}$ MES/glutamate buffer containing $20 \mu \mathrm{M}$ taxol and stored at $-80^{\circ} \mathrm{C}$.

Sarkosyl extraction. To obtain Sarkosyl-insoluble fractions, a modified version of a previously published method was used (Planel et al., 2009). Briefly, RIPA-insoluble pellets were homogenized in 1\% Sarkosyl and incubated at room temperature for $30 \mathrm{~min}$ with constant shaking. Samples were centrifuged for $1 \mathrm{~h}$ at $100,000 \times g$ at $20^{\circ} \mathrm{C}$, and the supernatant and pellet were separated and diluted in $\mathrm{O}^{+}$buffer $(62.5 \mathrm{~mm}$ Tris- $\mathrm{HCl}$, pH 6.8, 10\% glycerol, 5\% 2-mercaptoethanol, 2.3\% SDS, 1 mм EGTA, 1 mM EDTA, $1 \mathrm{~mm}$ PMSF, $1 \mathrm{~mm} \mathrm{Na} \mathrm{VO}_{4}, 1 \mathrm{~mm} \mathrm{NaF}$, and $10 \mu \mathrm{l} / \mathrm{ml}$ of protease inhibitor cocktail P8340; Sigma-Aldrich). Samples were boiled for $3 \mathrm{~min}$ and stored at $-20^{\circ} \mathrm{C}$

Western blot and analysis. Total protein concentrations for each sample were determined by Pierce Bicinchoninic Acid protein assay (Thermo Fisher Scientific). Equal amounts of protein for each sample were loaded and separated using SDS-PAGE on $10 \%, 10 \%-20 \%$ or $10.5 \%-14 \%$ Criterion pre-cast Tris-HCl gels (Bio-Rad). Protein was transferred to nitrocellulose membranes (Bio-Rad), which were blocked with 5\% BSA (Sigma-Aldrich) in $1 \times$ TBST buffer (10 mm Tris-Base (Sigma-Aldrich), $0.2 \mathrm{M} \mathrm{NaCl}$ (Macron Chemicals), 0.1\% Tween-20 (Sigma-Aldrich), pH 7.4. Protein was immunoblotted with Tau13 (1:60,000, BioLegend), GAPDH (14C10, Cell Signaling Technology, 1:4000), Tau46 (4019T, Cell Signaling Technology, 1:10,000), $\beta$-III tubulin (79-720, ProSci, 1:10,000), synaptophysin (SY38 ab8049, Abcam, 1:10,000), PSD-95 (2507S, Cell Signaling Technology, 1:10,000), CP13 (pSer202, Peter Davies, 1:1000), PHF1 (pSer396/404, Peter Davies, 1:1500), rabbit antihuman tau (ab74391, Abcam, 1:10,000), $\alpha$-tubulin (Thermo Fisher Scientific, DM1A 62204, 1:10,000), MAPK (05-481, Millipore, 1:250), and JNK/SAPK1 (06-748, Millipore, 1:5000) antibodies. For total protein analysis, REVERT total protein stain kit (LI-COR Biosciences, product \#926-11010) was used to obtain normalized phospho-tau to total tau ratios on separate Western blots, after ab74391 was discontinued. To visualize immunoreactivity using a LiCor imaging system (LI-COR Biosciences), IRDye-linked goat anti-mouse $800 \mathrm{CW}$ and goat anti-rabbit 680LT secondary antibodies were used (LI-COR Biosciences, 1:100,000). Immunoreactivity was quantified by densitometry using OptiQuant version 3 software.

ELISA. Samples were run in duplicate in the Human Total Tau V-Plex ELISA kit (Meso Scale Discovery) according to the manufacturer's instructions. To be within the range of detection for this assay, extracts were diluted in Diluent 35 at the following ratios: TBS, 1:10,000; G-E, 1:5000; S-E, 1:2000; and P-E, 1:150.

Half-life measurements. Doxycycline chow (DOX) (Diet 7013, $200 \mathrm{mg}$ / $\mathrm{kg}$ ) was administered to 8 -week-old rT1 and rT2 mice 3 times per week for $0,1,3,6,11,16$, and $21 \mathrm{~d}$, resulting in suppression of $h$ Tau $m R N A$ expression for $0,2,5,10,15$, and $20 \mathrm{~d}$, because it takes $24 \mathrm{~h}$ to suppress hTau suppression in these mouse lines (data not shown). hTau protein levels measured by ELISA (ng hTau/mg brain mass) were log transformed and plotted over days on DOX chow. Simple linear regressions were used to determine the slopes $\left(k^{\prime}\right)$ of rT1 and rT2 lines, and the half-life $\left(t_{1 / 2}\right)$ was determined based on the integrated rate law of first- 
order chemical reactions: $k=2.303 \times k^{\prime}$; and $t_{1 / 2}=0.693 / k$ (Yamada et al., 2015).

Morris Water Maze. The investigators were blinded to the group allocation, and mice were randomized to control for potential age, gender, and litter effects. Sample sizes were estimated based on our unpublished data. Spatial reference memory was measured by using a modified Morris Water Maze with a protocol tailored for rapid learning in the 129/FVB F1 mice (Weitzner et al., 2015). Mice were prehandled for 5 sessions during the week preceding testing to gradually introduce the animals to handler manipulations and exposure to the transportation devices (beaker and scoop). In addition, there was a gradual increase in the time that mice were in home cages without micro-isolator lids and then outside of their cage in an open field and under brighter light conditions without exposure to water. Mice received visible-platform training for $5 \mathrm{~d}$, with three trials per day, followed by hidden-platform training for $8 \mathrm{~d}$, with two trials per day. The path lengths to the hidden platform were averaged over $2 \mathrm{~d}$ periods (two trials per day, four trials total) for statistical analysis. There was a $3 \mathrm{~d}$ rest period between the visible- and hidden-platform training sessions. Three probe trials of $30 \mathrm{~s}$ duration each, during which the platform was removed from the pool, were performed $72 \mathrm{~h}$ after the 8th, 12th, and 16th trials of hidden-platform training, after days 4,6 , and 8 of hidden training, respectively. Hidden training continued immediately after the first and second probe trials. Accordingly, there was a $72 \mathrm{~h}$ interval between hidden trials 8 and 9 (days 4 and 5) and between trials 12 and 13 (days 6 and 7). The quadrant occupancy scores of the three probe trial scores were averaged for statistical analysis. For developmental suppression experiments, DOX chow (40 mg/kg, Envigo) was administered 3 times per week to either pregnant T1 and T2 dams (Diet 5015) upon separation from sires or to weaned litters (Diet 7013). This dosage of DOX was chosen because higher doses cause placental abnormalities and fetal loss (Moutier et al., 2003). rT1 and rT2 $\mathrm{hTau}^{+/-} \mathrm{tTA}^{+/-}$mice in addition to $\mathrm{hTau}^{-1-} \mathrm{tTA}^{-1-}$ and $\mathrm{hTau}^{-1-} \mathrm{tTA}^{+/-}$littermates included in this study all received the DOX chow diet. Upon switching diets between DOX and regular chow, clean cages were used. All trials were monitored, and performance measures were extracted using a computerized tracking system (Noldus EthoVision XT 10; Noldus Information Technology). hTau ${ }^{-1-} \mathrm{tTA}^{-1-}$ and $\mathrm{hTau}^{+-} \mathrm{tTA}^{+-}$mice of the same line underwent water maze training at the same time to control for batch effects.

Mitochondrial length and transport measurements. Mitochondria were examined using methods validated previously (Vossel et al., 2015). Primary hippocampal cultures were established using postnatal day 0 pups. The hippocampus was dissected in cold Earle's balanced salt solution (Invitrogen) and digested with $10 \mathrm{U} / \mathrm{ml}$ papain (Worthington Biochemical) in Earle's balanced salt solution at $37^{\circ} \mathrm{C}$ for $15 \mathrm{~min}$. Low ovomucoid solution containing $0.15 \%$ BSA (Sigma-Aldrich), 0.15\% trypsin inhibitor (Sigma-Aldrich) in Dulbecco's PBS (DPBS) with calcium and magnesium (Invitrogen), and $66.6 \mathrm{U} / \mathrm{ml}$ deoxyribonuclease I (SigmaAldrich) was added to stop the digestion reaction. After 5 min, cells were suspended in fresh low ovomucoid solution. Debris was removed with a BD $70 \mu \mathrm{m}$ nylon strainer, and the cells were spun at $341 \times g$ for $7 \mathrm{~min}$. Cell pellets were then resuspended in warm Neurobasal A medium (Invitrogen) containing 2\% B27 (Invitrogen), 0.5 mm GlutaMAX (Invitrogen), and $100 \mathrm{U} / \mathrm{ml}$ penicillin/streptomycin (Invitrogen).

Hippocampal primary neurons were plated on glass-bottom microwell dishes (MatTek) that had been coated overnight with $0.5 \mathrm{mg} / \mathrm{ml}$ poly-L-lysine (Sigma-Aldrich) in borate buffer and for $1-2 \mathrm{~h}$ with 0.005 $\mathrm{mg} / \mathrm{ml}$ laminin from Roche Diagnostics in neurobasal A. Hippocampal cells were plated at a density of 350,000 cells per $10 \mathrm{~mm}$ microwell dish. After 24 h, 5-fluoro-2'-deoxyuridine (Sigma-Aldrich) was added at a final concentration of $7.15 \mu \mathrm{g} / \mathrm{ml}$ to inhibit glial growth. Half-medium changes were performed every $7 \mathrm{~d}$ to maintain culture health.

Transfections of hippocampal cultures were performed on DIV 8-11. Plasmids used (provided by K. Vossel, University of Minnesota) included an FUGW EGFP construct (Lois et al., 2002) and mito-RFP, which was constructed by fusing the mitochondrial-targeting sequence of human isovaleryl coenzyme A dehydrogenase to the $\mathrm{N}$ terminus of RFP within the pDsRed1-N1 vector backbone containing a CMV promoter (Takara Bio) (Yoon et al., 2003). After removal of conditioned medium, cells were washed once with warm DPBS without calcium or magnesium (Invitrogen) and immediately placed into $500 \mu \mathrm{l}$ warm transfection medium consisting of Neurobasal A (Invitrogen) with $0.5 \mathrm{~mm}$ GlutaMAX (Invitrogen), $1 \mathrm{~mm}$ kynurenic acid (Sigma-Aldrich), and $10 \mathrm{~mm}$ magnesium chloride (Sigma-Aldrich). To prepare transfection complexes, Lipofectamine 2000 (Invitrogen) was added to OptiMEM reduced serum medium with GlutaMAX (Invitrogen) at a ratio of $1.35 \mu$ l Lipofectamine per $25 \mu$ l OptiMEM. In separate tubes, plasmid DNA was combined in amounts that were equimolar to $1 \mu \mathrm{g}$ FUGW per $25 \mathrm{ml}$ OptiMEM. After incubating separately $5 \mathrm{~min}$, the Lipofectamine-OptiMEM and DNAOptiMEM solutions were combined and incubated at room temperature while covered for $25 \mathrm{~min}$. Then, $50 \mathrm{ml}$ of combined transfection solution was added to each microwell dish. Neuronal cultures were then incubated for $30 \mathrm{~min}$ at $37^{\circ} \mathrm{C}$. Finally, cells were washed twice with warm DPBS and immediately placed in $3 / 4$ conditioned medium and $1 / 4$ fresh medium.

Live imaging of axonal mitochondria was conducted on DIV 10-13 with a Nikon inverted TiE deconvolution microscope system with Ibidi live cell environmental chamber, PFS Perfect Focus III focus lock technology, LED Light engine, motorized stage, Zyla 5.5MP sCMOS camera, and Nikon NIS-Elements Viewer imaging software version 5.10. Objective lenses were $10 \times$ (PlanFluor, NA 0.25), $20 \times$ (PlanFluor, NA 0.25 ELWD), and $40 \times$ (Plan Apo, NA 0.95). EGFP and RFP were illuminated at wavelengths of 470 and $555 \mathrm{~nm}$, respectively.

At the beginning of each section, positions of neurons with easily identifiable axons were recorded at $10 \times$ magnification, using FUGW (EGFP) as a morphology marker. Cells exhibiting axonal beading were excluded from imaging sessions. Axons were distinguished as the longest neurite ( $\geq 3$ times longer than other neurites), validated previously (Vossel et al., 2015). Imaging of axonal mitochondria using mito-RFP was performed for each axon with a $40 \times$ objective. Images were acquired every $1 \mathrm{~s}$ for $150 \mathrm{~s}$, with an exposure time of $100 \mathrm{~ms}$ per frame.

Images were processed in Fiji using the Multiple Kymograph and tsp050706 plugins. Moving mitochondria were defined as showing displacement of at least $2 \mu \mathrm{m}$, which was the average length of mitochondria observed previously (Vossel et al., 2015). Velocity was measured for each moving mitochondrion by averaging its total velocity, including brief pauses, while in the image frame. Lengths of mitochondria were measured on the kymographs. Pixels were converted to micrometers based on the calibration of the objective.

Fluorescent immunohistochemistry, imaging, and analysis. At 2 months of age, mice were transcardially perfused with $50 \mathrm{ml}$ PBS followed by 50 $\mathrm{ml} 4 \%$ PFA. Brains were removed, postfixed overnight in 4\% PFA, and cryoprotected for $48 \mathrm{~h}$ in $30 \%$ sucrose. Brains were coronally cryosectioned at $40 \mu \mathrm{m}$, and all subsequent incubations and washes were performed free-floating in 24-well plates.

Following three washes of PBS $+0.1 \%$ Triton X-100, sections were placed in $1 \% \mathrm{NaBH}$ for $20 \mathrm{~min}$ at room temperature. Sections were washed $5 \times 15 \mathrm{~min}$ in PBS $+0.1 \%$ Triton X-100. Sections were incubated in an antigen retrieval sodium citrate buffer (Reveal Decloaker) for 30 $\min$ at $80^{\circ}$ and allowed to cool for $30 \mathrm{~min}$. Sections were washed $3 \times 15$ min in PBS $+0.1 \%$ Triton X-100 and transferred to blocking buffer of PBS $+0.5 \%$ Triton X-100, 5\% normal goat serum. Sections were incubated for $48 \mathrm{~h}$ at $4^{\circ}$ in primary antibody solution of PBS $+0.3 \%$ Triton $\mathrm{X}-100,3 \%$ normal goat serum, at a 1:1000 dilution (DNA/RNA Oxidative Damage Oh8dG, QED Bioscience).

Following three washes of PBS $+0.1 \%$ Triton X-100, sections were incubated for $1 \mathrm{~h}$ at room temperature in secondary antibody solution of PBS $+0.3 \%$ Triton X-100, 3\% normal goat serum, at a 1:1000 dilution (Goat Anti-Mouse IgG H\&L AlexaFluor-594, Abcam). Sections were washed $3 \times 15 \mathrm{~min}$ in PBS and placed onto Superfrost slides. Sections were treated for $30 \mathrm{~s}$ with TrueBlack Lipofuscin Autofluorescence Quencher (Biotium) and washed $3 \times 15$ min with PBS. Slides were coverslipped with Vectashield mounting media containing DAPI (Vector Laboratories). RNase treatment made no difference in signal intensity in pilot studies, so this was not used for experimental tissue.

After blinding the investigator, samples were imaged on a Nikon NiE C2 Upright Confocal microscope, and $10 \times$ images were taken of the dentate gyrus of the hippocampus, CA1 region of the hippocampus, and 
the cortex. Analysis of the AlexaFluor-594 signal intensity was performed in Fiji/ImageJ. The pyramidal layer of the CA1 region of the hippocampus, the granular cell layer of the dentate gyrus, and all cortical layers were outlined as the ROI using the polygon tool. The integrated density (area $\times$ mean intensity) of the ROI was measured to account for differences in area between samples.

Experimental design and statistical analysis. Power analyses on preliminary data were performed for pTau quantification, hTau ELISA, and Morris Water Maze. For pTau detection by Western blot, it was determined that an $n$ of 6 mice would be sufficient to have an $84 \%$ chance of detecting a $39 \%$ difference in means at a significance level of 0.05 . For ELISA experiments, it was determined that an $n$ of 4 mice per line would be sufficient to have a $91 \%$ chance of detecting a $21 \%$ difference in means. Therefore, a group size of 6 was chosen for tau quantification experiments by Western blot and ELISA. For behavioral experiments, it was determined that a sample size of 12 would be sufficient for a $64 \%$ chance of detecting a $41 \%$ difference in group means.

For half-life experiments, $\mathrm{R}$ programming language was used to conduct multiple linear regressions for detecting differences between linear regression slopes. Statistical analyses for all other data were conducted using Prism version 7.00 software (GraphPad Software). Unpaired twotailed $t$ tests were used to detect differences between rT1 and rT2 hTau mRNA, protein (by Western blot and ELISA), phosphorylated hTau at 8 weeks of age, and NM versus P301L hTau levels in MT binding experiments. Two-way ANOVAs with Sidak's multiple-comparisons test were used for comparing human and mouse tau levels in rT1 and rT2 mice, as well as hTau levels and phosphorylation with or without DOX suppression. Simple linear regression was used to calculate slopes, $y$ intercepts, and $R^{2}$ values for NM and P301L hTau half-life data. Bonferronicorrected unpaired two-tailed $t$ tests were used to compare phosphorylation levels of hTau in rT1 and rT2 at 3, 5, and 7 weeks of age. Two-way ANOVAs with Tukey's multiple-comparisons test were used to detect differences in hTau levels and phosphorylation with 4 or 12 weeks of DOX suppression in $\mathrm{rT} 1$ and rT2.

Two-way repeated-measures ANOVAs with Sidak's multiple-comparisons tests were used for Morris Water Maze visible and hidden trial data to determine whether rT1, rT2, and nontransgenic littermate path lengths changed over time. Two-way repeated-measures ANOVAs with Tukey's multiple-comparisons tests were used for Water Maze visible and hidden data to determine whether rT1 and rT2 path lengths differed from 4 and 12 week DOX suppression groups. One-way ANOVAs followed by Holm-Sidak's multiple-comparisons tests with target $(\mathrm{T})$ as the control column were used to assess search bias in Water Maze probe trial data to separately determine whether each group spent more time in the target than the other 3 quadrants (Sakimura et al., 1995). One-way ANOVAs followed by Holm-Sidak's multiple-comparisons tests were also used to compare 0,4 , and 12 week suppression groups and to compare $\mathrm{hTau}^{-1-} \mathrm{tTA}^{-1-}, \mathrm{hTau}^{-1-} \mathrm{tTA}^{+/-}$, and $\mathrm{hTau}^{+/-} \mathrm{tTA}^{+/-}$genotypes in time spent only in the target quadrant. Two-tailed MannWhitney tests were used to directly compare the percent time spent only in the target quadrant between rT1 or rT2 and nontransgenic littermates. A Kruskal-Wallis test with Dunn's multiple-comparisons test was used to analyze mitochondrial length data. Two-way ANOVAs with Sidak's multiple-comparisons tests were used to determine whether there were differences in oxidative stress between $\mathrm{rT} 1$ and $\mathrm{rT} 2$ and between each of the genotypes in each brain region. Two-way ANOVAs with Sidak's multiple-comparisons test were used to test whether postnatal brain mass differed between genotypes, whether $\mathrm{rT} 1$ brain mass differed from rT2, and whether DOX suppression affected rT1 and rT2 brain mass. In all cases, $p<0.05$ was considered to be statistically significant.

\section{Results}

\section{Elevated steady-state levels of 4R NM compared with P301L hTau}

Responder T1 and T2 mice were generated using site-specific targeting of an hTau transgene downstream of the CollA1 3' untranslated region in modified embryonic stem cells. Correct single-copy integration was confirmed using PCR assays and whole-genome sequencing (Gamache et al., 2019). The transgene consists of the cDNA sequence for the $0 \mathrm{~N} 4 \mathrm{R}$ isoform of hTau, flanked by noncoding regions of the murine Prion protein gene to enhance brain expression (Santacruz et al., 2005), and regulated by a TRE promoter. T1 mice harbor an NM hTau transgene, whereas T2 harbor a P301L mutant hTau transgene. Responder T1 and T2 mice are crossed to the CaMKII $\alpha$-tTA line (Mayford et al., 1996) to generate Tet-OFF bigenic rT1 and rT2 ( $\mathrm{r}$ indicates regulatable) progeny that express $0 \mathrm{~N} 4 \mathrm{R}$ hTau selectively in forebrain neurons, except in the presence of DOX.

Despite expressing similar levels of hTau mRNA in the forebrain (Fig. 1A), rT1 mice had elevated steady-state levels of hTau protein at 8 weeks of age $\left(t_{(21)}=4.60, p=0.0002,95 \%\right.$ CI $[-1.10$, $-0.42]$ ) (Fig. 1B). A difference in electrophoretic mobility also suggested a difference in post-translational modifications (Fig. $1 C$ ). A human tau ELISA (Meso Scale Discovery) confirmed the difference in hTau steady-state levels $\left(t_{(10)}=5.06, p=0.0005\right.$, 95\% CI $[-112.3,-43.66]$ ) (Fig. 1D). To quantify fold overexpression of hTau relative to endogenous mouse tau, phosphatase-treated extracts from rT1 and rT2 were compared with activator-only (tTA) brains using a pan-tau antibody, which revealed 12.6-fold overexpression in rT1 and 6.2-fold in rT2 (tTA vshTau $F_{(1,20)}=73.71, p<0.0001 ;$ rT1 vs rT2 $F_{(1,20)}=12.01, p=$ 0.0024 ) (Fig. $1 E, F)$. rT1 hTau overexpression was significantly higher than that of rT2 $(p=0.0002)$.

\section{Longer half-life of 4R NM than P301L hTau}

Because $h$ Tau mRNA levels are similar between rT1 and rT2, it is unlikely that hTau protein is higher in rT1 due to a higher rate of production. We therefore tested the hypothesis that the elevation in 4R NM hTau steady-state levels was due to a slower rate of degradation by measuring the half-life in 8-week-old rT1 and rT2 mice in a manner similar to a previous study (Yamada et al., 2015), taking advantage of DOX-mediated suppression. Using ELISA measurements, we found that hTau levels declined with longer periods of transgene suppression $\left(F_{(3,80)}=443.9, R^{2}=\right.$ $0.94, p<0.000$ ), and that the clearance rate of soluble hTau was slower in 8-week-old rT1 than rT2 forebrains (Fig. 2A; Table 3).

To determine whether clearance of $4 \mathrm{R}$ NM hTau was impaired in a specific subcellular compartment, forebrains were fractionated into G-E, S-E, and P-E fractions (Fig. 2B). Again, hTau levels declined with longer periods of transgene suppression in the G-E $\left(F_{(3,80)}=147.6, R^{2}=0.85, p<0.000\right)$, S-E $\left(F_{(3,80)}\right.$ $\left.=115.9, R^{2}=0.81, p<0.000\right)$, and P-E fractions $\left(F_{(3,80)}=125.5\right.$, $R^{2}=0.83, p<0.000$ ) (Table 3 ). In addition, NM hTau degradation was significantly slower than P301L in the P-E fraction (Fig. $2 C$; Table 3). The half-life of NM hTau was consistently longer than for P301L hTau in all fractions tested (Table 3). These results demonstrate that hTau steady-state levels are higher in rT1 than rT2 because of a slower clearance rate, and suggest that hTau degradation is impaired primarily in the postsynaptic compartment. Although only a small fraction of total hTau is localized to the postsynaptic compartment, reduced clearance may begin early and compound over time to cause elevated levels by 8 weeks of age.

\section{Hyperphosphorylation of 4R NM hTau compared with P301L hTau}

We observed altered electrophoretic mobility of NM compared with P301L hTau, suggesting a difference in post-translational modifications (Fig. 1C). In addition, some studies indicate that 
A

hTau mRNA

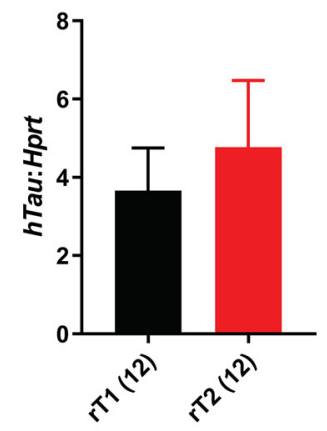

D

hTau protein (ELISA)

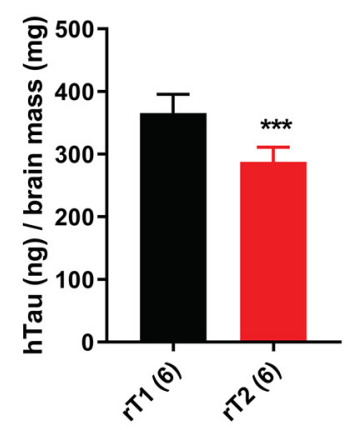

B

hTau protein (Western blot)

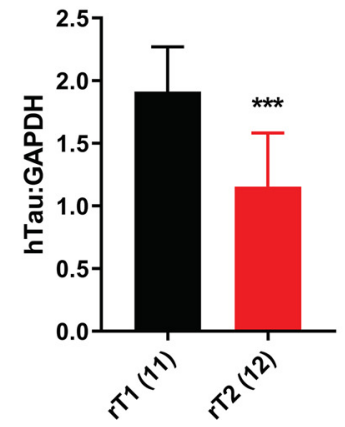

E

FL Tau protein

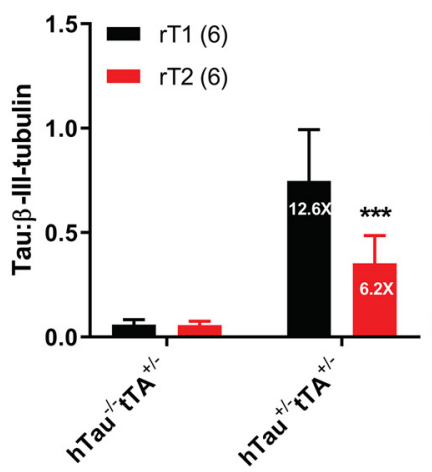

F

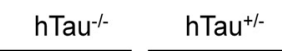

Tau

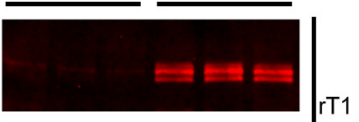

$\beta$-III tub.

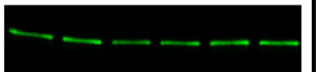

Tau

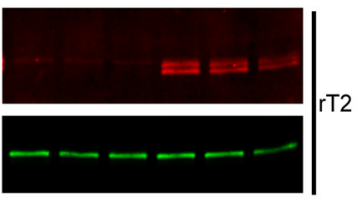

Figure 1. Higher steady-state levels of 4R NM than P301L hTau. $A$, Relative qRT-PCR shows similar $h$ Tau mRNA expression in 8-week-old rT1 and rT2 forebrains. $h$ Tau mRNA was not detected in $\mathrm{T} 1$ or T2 responders, demonstrating a lack of leaky transgene expression in the absence of the activator transgene (data not shown). $\boldsymbol{B}$, Densitometric analysis of Western blots shows higher steady-state levels of NM than P301L hTau in forebrains of 8-week-old mice. C, Representative immunoblots for hTau (Tau13 antibody) and GAPDH protein for data in $\boldsymbol{B}$. Proteins were extracted in RIPA buffer and run on a 10\%-20\% Tris-HCl gel. D, Soluble tau extracted in TBS buffer and measured by human tau ELISA also shows higher steady-state levels of NM than P301L hTau in 8-week-old forebrains. $\boldsymbol{E}$, Quantification of full-length (FL) human and mouse tau in phosphatase-treated samples from 8-week-old forebrains, showing higher overexpression of hTau in rT1 (12.6-fold) than rT2 (6.2-fold) relative to tTA ${ }^{+/-}$mice. $\boldsymbol{F}$, Representative immunoblots for human and mouse tau (Tau46) and $\beta$-III tubulin for data in $\boldsymbol{E}$. Proteins were extracted in RIPA buffer, treated with phosphatase, and run on a $10.5 \%-14 \%$ Tris- $\mathrm{HCl}$ gel. $n$ values are in parentheses. Graphs represent group mean \pm SD. ${ }^{* *} p<0.001$.

A

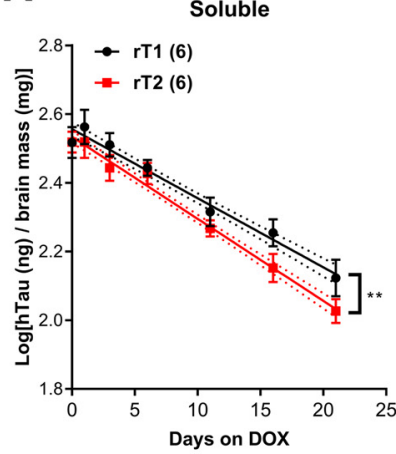

B

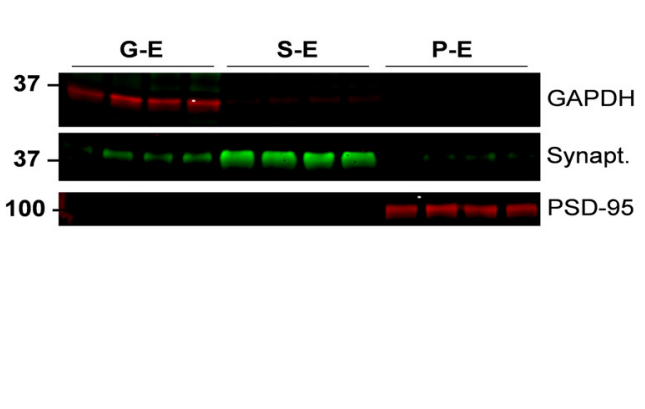

C

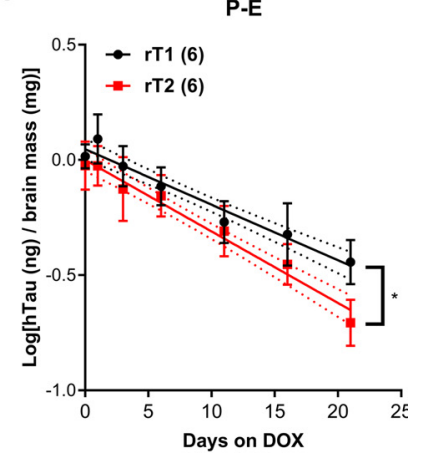

Figure 2. Slower clearance rate of 4R NM than P301L hTau. $A$, The clearance rate of soluble NM hTau is slower than P301L hTau (see also Table 3). B, Validation of biochemical fractionation method into G-E, S-E, and P-E compartments by immunoblotting for GAPDH, synaptophysin, and PSD-95. Molecular weight in kilodaltons (KDa) is indicated on the left. Proteins were run on a 10\% Tris-HCI gel. $C$, The clearance rate of NM hTau is slower than P301L hTau in the P-E fraction (see also Table 3). Symbols on graphs represent group mean \pm SE. Solid lines indicate linear regressions. Dotted lines indicate SE. $n$ values are in parentheses. ${ }^{*} p<0.05,{ }^{* *} p<0.01$.

NM tau has a higher propensity to become phosphorylated than P301L tau (Terwel et al., 2005; Orr et al., 2012; Rodríguez-Martín et al., 2016). Therefore, we next determined whether $4 \mathrm{R}$ NM hTau was hyperphosphorylated compared with P301L hTau in 8-week-old rT1 and rT2 forebrains by immunoblotting with a series of antibodies that recognize well-known tau phosphoepitopes in human tauopathy postmortem tissue.
While some antibodies showed no differences between $\mathrm{rT1}$ and rT2, including AT8 (pSer202/pThr205) and PG5 (pSer409) (data not shown), CP13 (pSer202) and PHF-1 (pSer396/ pSer404) revealed significantly higher phosphorylation levels of NM than P301L hTau (CP13: $t_{(10)}=11.47, p<0.0001,95 \% \mathrm{CI}$ $[-0.27,-0.18]$; PHF- $1: t_{(10)}=6.18, p=0.0001,95 \%$ CI $[-0.17$, $-0.08]$ ) (Fig. 3A,B). NM hTau was also hyperphosphorylated 
Table 3. Summary of 4R NM and P301L hTau half-life and regression data ${ }^{a}$

\begin{tabular}{|c|c|c|c|c|c|c|}
\hline Fraction & $\begin{array}{l}\text { NM hTau } \\
\text { half-life } \\
\text { (days) }\end{array}$ & $\begin{array}{l}\text { P301L hTau } \\
\text { half-life } \\
\text { (days) }\end{array}$ & $\begin{array}{l}\operatorname{SLR} R^{2} \\
\text { (NM, P301L) }\end{array}$ & $\begin{array}{l}\text { SLRy } \\
\text { intercept } \\
\text { (NM, P301L) }\end{array}$ & $\begin{array}{l}\text { SLR slope } \\
\text { (NM, P301L) }\end{array}$ & $\begin{array}{l}\text { MLR } \\
p \text { value }\end{array}$ \\
\hline Soluble & 15.0 & 12.5 & $0.92,0.96$ & $2.56,2.53$ & $-0.020,-0.024$ & 0.00292 \\
\hline $\mathrm{G}-\mathrm{E}$ & 12.6 & 11.1 & $0.86,0.83$ & $2.14,2.08$ & $-0.024,-0.027$ & 0.1762 \\
\hline S-E & 18.5 & 15.6 & $0.78,0.80$ & $1.68,1.61$ & $-0.016,-0.019$ & 0.14309 \\
\hline P-E & 12.5 & 9.7 & $0.78,0.84$ & $0.047,0.00014$ & $-0.024,-0.031$ & 0.0214 \\
\hline
\end{tabular}

${ }^{a}$ Half-lives of NM and P301L hTau, as measured by the experiment shown in Figure 2 in rT1 and rT2 mice, were calculated using the integrated rate law for first-order chemical reactions $\left(t_{1 / 2}=0.693 /\left(2.303 \times k^{\prime}\right)\right.$ (Yamada et al., 2015), where $k^{\prime}$ is the slope of the log-transformed values of tau plotted over time on DOX. Coefficients of determination $\left(R^{2}\right)$ values, $y$ intercepts, and slopes from simple linear regressions (SLR) are listed. Multiple linear regressions (MLR) were used to test for differences between slopes, and $p$ values are shown.

compared with P301L hTau in the biochemically isolated postsynaptic fraction $\left(\mathrm{CP} 13: t_{(10)}=3.32, p=0.0078,95 \% \mathrm{CI}[-0.31\right.$, $-0.062]$; PHF-1: $t_{(10)}=6.35, p<0.0001,95 \%$ CI $[-0.31$, $-0.15]$ ) (Fig. $3 C, D, E$ ). Elevated NM hTau phosphorylation compared with P301L hTau could be detected as early as 5 weeks of age $\left(\mathrm{CP} 13: t_{(6)}=4.76, p=0.0093,95 \%\right.$ CI $[-0.402,-0.13]$; PHF-1: $t_{(6)}=6.61, p=0.0018,95 \%$ CI $\left.[-0.33,-0.15]\right)$, and continued at 7 weeks (CP13: $t_{(5)}=7.38, p=0.0021,95 \% \mathrm{CI}$ $[-0.37,-0.18]$; PHF- $1: t_{(5)}=4.11, p=0.028,95 \%$ CI $[-0.44$, $-0.10])$, suggesting that this could be a neurodevelopmental phenomenon (Fig. $3 F, G$ ).

There is much overlap between the sites highly phosphorylated on tau during development and in aging-related neurodegenerative diseases, but normal developmental phosphorylation is insufficient to induce tau aggregation and insolubility (Yu et al., 2009). To determine whether phosphorylation of 4R NM hTau in young mice was associated with insolubility, protein from forebrains of 8-week-old mice was extracted in Sarkosyl. No high-molecular-weight hTau species $>55 \mathrm{kDa}$ were observed (data not shown), indicating that the phosphorylation in rT1 brains does not induce the formation of insoluble aggregates.

\section{Developmental transgene suppression temporarily reduces NM hTau levels and phosphorylation}

The predominance of $3 \mathrm{R}$ tau isoforms in the developing mouse brain (McMillan et al., 2008) is essential for neurite polarity establishment (Caceres and Kosik, 1990) and neurite outgrowth (Hanemaaijer and Ginzburg, 1991; Sayas et al., 2015). We therefore hypothesized that overexpression of $4 \mathrm{R}$ tau during a developmental period in which $3 \mathrm{R}$ normally predominates causes the abnormal molecular phenotype of NM hTau. To determine whether the elevation in steady-state levels and hyperphosphorylation of NM compared with P301L hTau was due to overexpression during development, and whether pathogenicity of NM hTau is established during a specific developmental window, we suppressed hTau and tTA-DNA binding with DOX for either the first 4 or 12 weeks of life (OFF $4 \mathrm{~W}$ and OFF $12 \mathrm{~W}$ groups). Following suppression, mice were taken off of DOX chow for 4 or 8 weeks, and brain tissue was collected. Importantly, hTau expression and tTA toxicity in these models are intrinsically linked. Suppression of tTA-DNA binding during development prevents the observed reduction of dentate gyrus granule cells in that line (Han et al., 2012), presumably by preventing off-target binding of the overexpressed tTA protein during this vulnerable period. However, we reiterate that this phenomenon is matched between rT1 and rT2.

Developmental suppression followed by 4 weeks of hTau and tTA expression lowered NM hTau levels $\left(F_{(2,29)}=6.96, p=\right.$ $0.0034)$, pSer202 phosphorylation $\left(F_{(2,29)}=24.96, p<0.0001\right)$, and pSer396/404 phosphorylation $\left(F_{(2,29)}=9.45, p=0.0007\right)$, whereas suppression had no effect on P301L hTau biochemistry (Fig. 4). There were also significantly higher levels of pSer202 phosphorylation of NM hTau than P301L hTau in 4-week-old nonsuppressed control mice $\left(F_{(1,29)}=46.96, p<0.0001\right)$ (Fig. 4). After 8 weeks of postsuppression expression, there was no effect of suppression and no difference between rT1 and rT2, except for pSer202 phosphorylation, which remained reduced in suppressed mice $\left(F_{(2,29)}=8.88, p=0.001\right)$ and remained higher in rT1 than rT2 $\left(F_{(1,29)}=31.41, p<0.0001\right)$. In conclusion, suppression of hTau and tTA-DNA binding for either 4 or 12 weeks reduced $4 \mathrm{R}$ NM hTau steady-state levels and phosphorylation to levels comparable with P301L hTau after 4 weeks of expression. However, these molecular phenotypes were partially or fully reversed after 8 weeks of expression, indicating that the effect of developmental transgene suppression on NM hTau regulation is only temporary.

Of note, we were not able to replicate differences in hTau steady-state levels (Fig. 1) and pSer396/404 phosphorylation (Fig. 3) in the 8-week-old nonsuppressed controls included in the DOX-suppression experiment (Fig. 4). As these were different groups of mice, we attribute these observations to litter effects. However, the pSer202 observation remained quite robust in the suppression experiment (Fig. 4), suggesting that this phosphorylation event occurs first and increases propensity for phosphorylation at pSer396 and pSer404 (Li and Paudel, 2006; Li et al., 2006), leading to elevated stability (Poppek et al., 2006; Ren et al., 2007). Our observations indicate that the timing of these events is highly variable in different litters of mice, and took longer in the mice included in the suppression experiment.

\section{rT1, but not rT2, mice exhibit cognitive impairments}

Behavioral studies to assess cognition in these lines were conducted before we were aware of the abnormal molecular phenotype of $4 \mathrm{R}$ NM hTau. Therefore, we originally predicted that the P301L mutation would be associated with spatial learning and memory deficits in the Morris Water Maze in 5-month-old rT2 mice. Nontransgenic littermates were used as internal controls for "batch effects," such as effects of season, times of day and week, and animal husbandry schedules in these experiments. However, cognitive phenotypes in rT1 and rT2 should be considered in relation to one another rather than to nontransgenic animals, which lack both hTau and tTA transgenes.

Both rT1 (main effect of day: $F_{(4,88)}=35.80, p<0.0001$ ) and rT2 (main effect of day: $F_{(4,88)}=43.76, p<0.0001$ ) path lengths to the visible platform were significantly reduced as training progressed, indicating sensorimotor acquisition of the task in both lines (Fig. 5A). Path lengths to the hidden platform also decreased as training progressed for both $\mathrm{rT} 1$ (main effect of day: $F_{(3,66)}=$ 7.521, $p=0.0002$ ) and rT2 (main effect of day: $F_{(3,66)}=9.752$, $p<0.0001$ ), indicating improvements in spatial navigation (Fig. $5 B)$. However, compared with nontransgenic littermates, we were surprised to find that 5-month-old rT1 but not rT2 mice exhibited learning deficits during visible-platform training (main effect of genotype: $\left.F_{(1,22)}=18.46, p=0.0003\right)$ and hiddenplatform training (main effect of genotype: $F_{(1,22)}=23.76, p<$ 0.0001) (Fig. $5 A, B$ ).

rT1 mice also exhibited deficits in spatial reference memory during probe trials. Search bias was detected in $\mathrm{Tau}^{-1-} \mathrm{tTA}^{-1-}$ mice $\left(F_{(3,44)}=15.79, p<0.0001\right)$ but not in $\mathrm{Tau}^{+/-} \mathrm{tTA}^{+/-}$rT1 mice $\left(F_{(3,44)}=3.72, p=0.018\right)$ (Fig. $5 C$ ). In addition, Tau $^{+/-}$ $\mathrm{tTA}^{+/-}$rT1 mice spent significantly less time in the target quadrant than nontransgenic littermates $(U=8, p<0.0001)$ (Fig. 
A
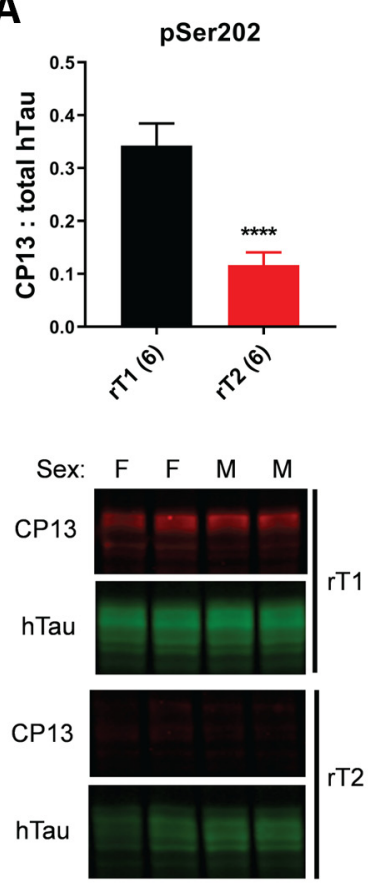

E

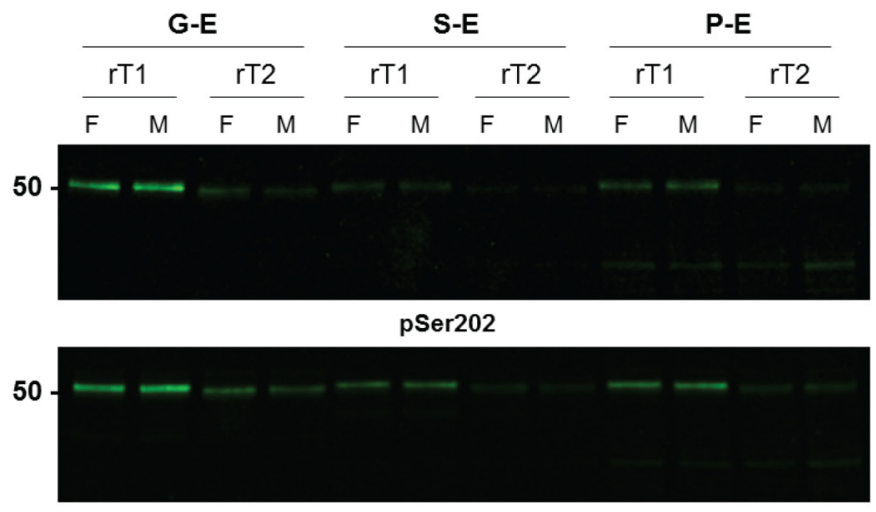

pSer396/Ser404
B
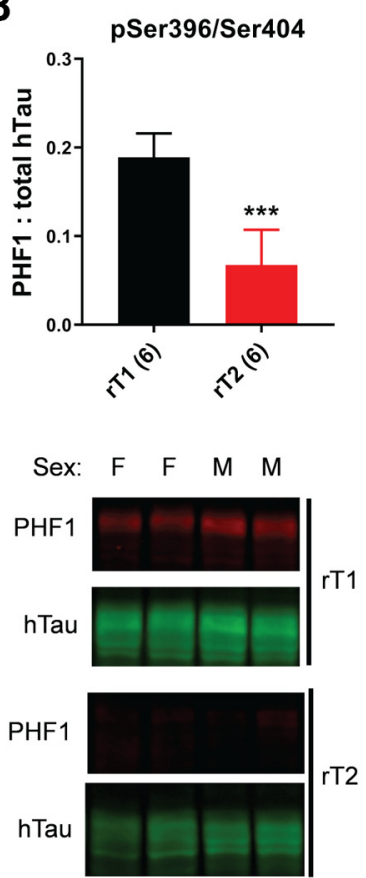

C

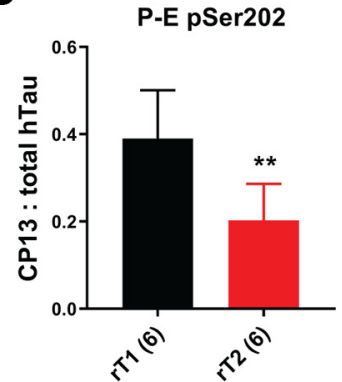

Sex: $F \quad F \quad M \quad M$

CP13

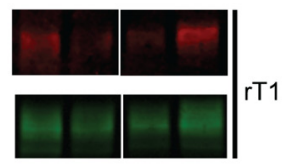

CP13

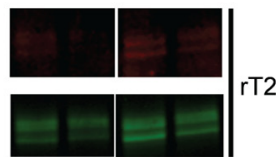

F

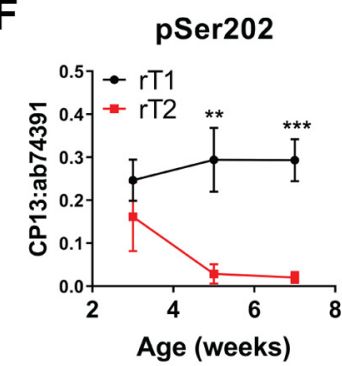

D

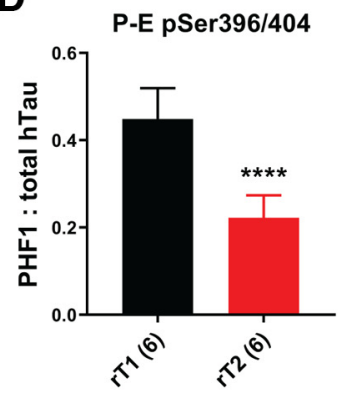

Sex: $F \quad F \quad M \quad M$

PHF1

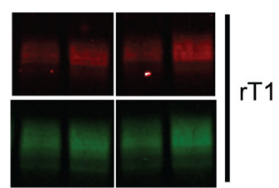

PHF1

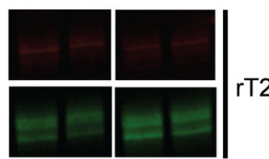

G pSer396/Ser404
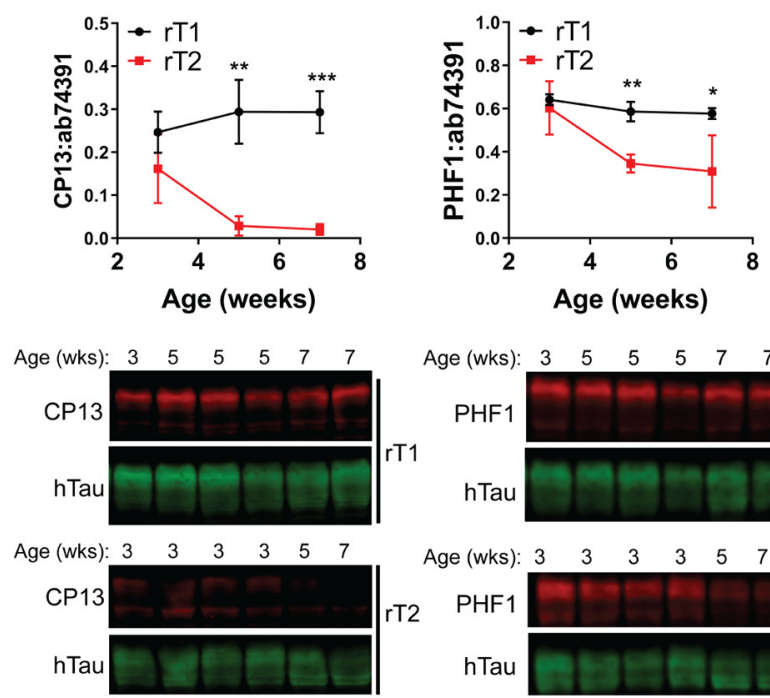

Figure 3. 4R NM hTau is hyperphosphorylated compared with P301L hTau by 5 weeks of age. Phosphorylation of hTau was greater in rT1 than in rT2 forebrains $(\boldsymbol{A}, \boldsymbol{B})$ and in the biochemically isolated P-E fraction (C, D) at 8 weeks of age. Top, Graphs summarize densitometric analyses of Western blots immunoblotted with CP13 (pSer202), PHF-1 (pSer396/Ser404), and ab74391 (hTau). $n$ values are in parentheses. Bottom, Representative Western blots for data in top panels with sex of the animals indicated above. E, Western blot comparison of phospho-hTau levels in subcellular compartments in female (F) and male (M) rT1 and rT2 brains, with targeted phospho-epitope indicated below each blot and kDa indicated on the left. Equal amounts of total protein (4 $\mu \mathrm{g}$ ) were loaded in each lane. NM hTau becomes hyperphosphorylated as early as 5 weeks of age at both pSer202 (F) and pSer396/404 (G) (rT1: $n=4,3$ weeks; $n=6,5$ weeks; $n=5,7$ weeks; rT2: $n=$ 6,3 weeks; $n=2,5$ weeks; $n=2,7$ weeks). $\boldsymbol{F}, \mathbf{G}$, Bottom, Representative blots with indicated ages of animals. Proteins were extracted in RIPA buffer and run on $10 \%$ Tris-HCl gels. Graphs represent group mean \pm SD. ${ }^{*} p<0.05,{ }^{* *} p<0.01,{ }^{* * *} p<0.001,{ }^{* * * *} p<0.0001$.

$5 C)$. This indicates either a pure learning deficit or a combined learning and spatial memory deficit in rT1 mice, associated with the abnormal molecular phenotype of 4R NM hTau. In contrast, 5-month-old rT2 mice exhibited no such deficits (Fig. 5D-F), suggesting that the low levels of P301L hTau phosphorylation at this age are insufficient to cause cognitive deficits in rT2.

Developmental transgene suppression prevents cognitive impairments in rT1

Developmental transgene suppression temporarily reduced $4 \mathrm{R}$ NM hTau steady-state levels and phosphorylation levels com- pared with P301L hTau (Fig. 4). To determine whether developmental suppression also prevents the cognitive deficits in rT1 mice, and whether pathogenicity is established during a specific developmental window, we again suppressed hTau expression and tTA-DNA binding with DOX for either the first 4 or 12 weeks of life (OFF 4W and OFF 12W groups). Following suppression, hTau and tTA were expressed for 5 months so as to match the expression period of impaired rT1 mice (ON 5M). Data from nonsuppressed mice are included for comparison; therefore, the same data from hTau ${ }^{+/-} \mathrm{tTA}^{+/-}$mice in Figure $5 A-F$ are included in Figures $5 G-L$ and 6. 

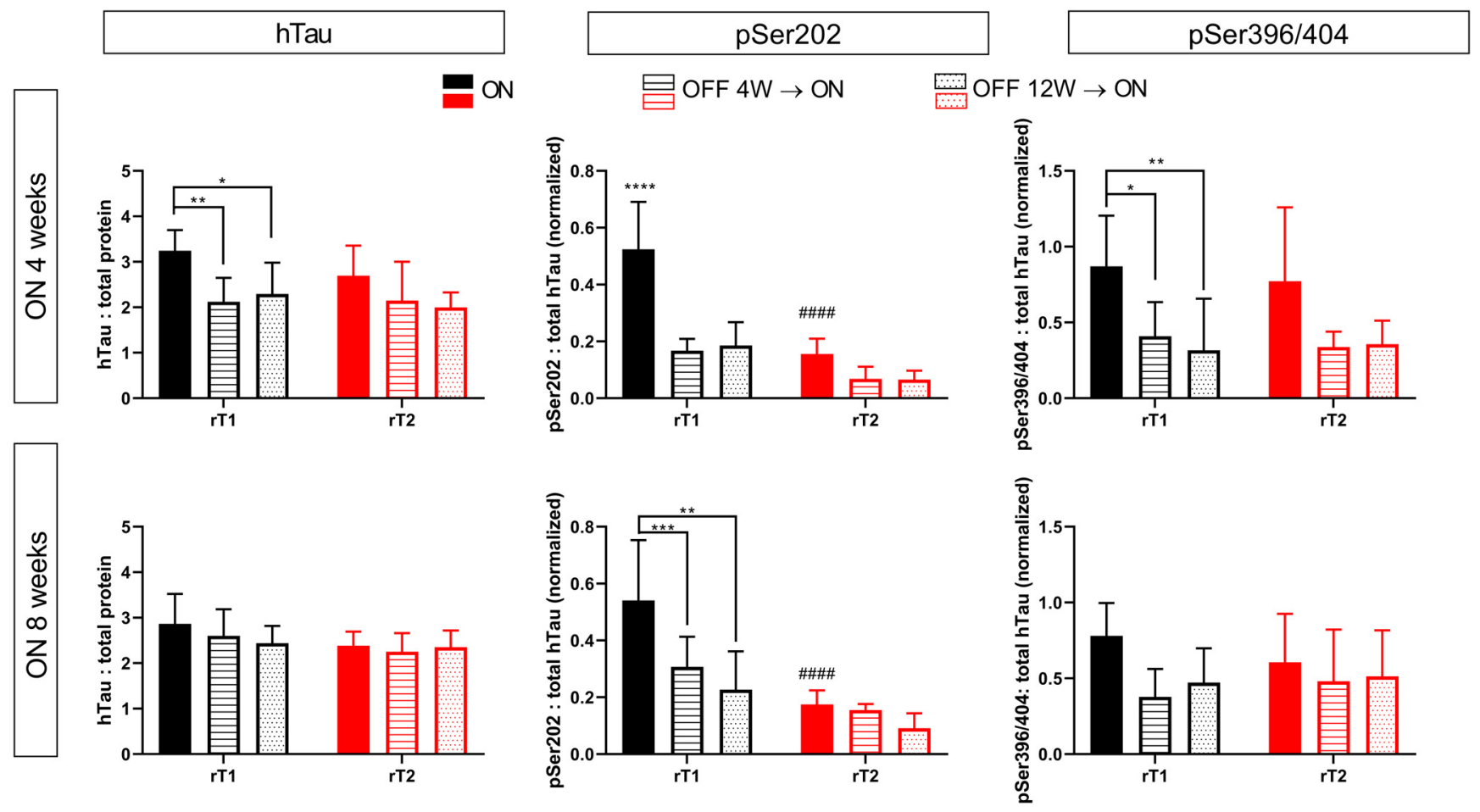

Figure 4. Developmental suppression temporarily reduces 4R NM hTau levels and phosphorylation in rT1 forebrains. Quantitative data from densitometry of Western blots for human tau normalized to total protein, and phospho-hTau at pSer202 and pSer396/404 normalized to total protein, represented as ratios to normalized total hTau levels (phospho-hTau:total protein::hTau: total protein). hTau was suppressed for either the first 4 weeks (OFF $4 \mathrm{~W} \rightarrow 0 \mathrm{~N}$ ) or 12 weeks (OFF $12 \mathrm{~W} \rightarrow 0 \mathrm{~N}$ ) of life followed by expression for 4 weeks (top row) or 8 weeks (bottom row). Nonsuppressed controls aged 4 or 8 weeks $(0 \mathrm{~N})$ are included to match the expression period of suppressed mice. $n=5$ or 6 per group. *Effect of DOX treatment. "Differences between rT1 and rT2. Graphs represent group mean $\pm S D .{ }^{*} p<0.05,{ }^{* *} p<0.01,{ }^{* * *} p<0.001,{ }^{* * * *} p<0.0001,{ }^{\# \# \#} p<0.0001$.

Both 4 and 12 weeks of suppression improved rT1 performance in visible-platform training $\left(F_{(2,33)}=12.9, p<0.0001\right)$ and hidden-platform training $\left(F_{(2,33)}=6.89, p=0.0032\right)$ compared with nonsuppressed rT1 mice (Fig. 5G,H). Developmental suppression of hTau also improved spatial reference memory in probe trials. Search bias was detected in both the 4 week suppres$\operatorname{sion}\left(F_{(3,44)}=17.6, p<0.0001\right)$ and 12 week suppression $\left(F_{(3,44)}\right.$ $=15.33, p<0.0001$ ) groups (Fig. $5 I$ ). In addition, suppressed rT1 spent significantly more time in the target quadrant than nonsuppressed mice $\left(F_{(2,33)}=10.37, p=0.0003\right)$. In contrast, suppression of hTau and tTA-DNA binding had no effect on rT2 cognition (Fig. 5J-L).

Suppressed rT1 and rT2 mice were also compared with $\mathrm{hTau}^{-1-} \mathrm{tTA}^{-1-}$ and $\mathrm{hTau}^{-1-} \mathrm{tTA}^{+/-}$littermates. In the 4 week suppression group, rT1 mice improved as visible training $\left(F_{(4,132)}=46.8, p<0.0001\right)$ and hidden training $\left(\mathrm{F}_{(3,99)}=\right.$ $21, p<0.0001)$ progressed, and no differences were detected between genotypes (Fig. 6A,B). All rT1 genotypes exhibited search bias in probe trials: $\mathrm{hTau}^{-1-} \mathrm{tTA}^{-1-}\left(F_{(3,44)}=32.41\right.$, $p<0.0001), \mathrm{hTau}^{-1-} \mathrm{tTA}^{+/-}\left(F_{(3,44)}=14.43, p<0.0001\right)$, and $\mathrm{hTau}^{+/-} \mathrm{tTA}^{+/-}\left(F_{(3,44)}=17.6, p<0.0001\right)$ (Fig. 6C). rT1 $\mathrm{hTau}^{+/-} \mathrm{tTA}^{+/-}$spent less time in the target quadrant than $\mathrm{hTau}^{-1-} \mathrm{tTA}^{-1-}$ mice $\left(F_{(2,33)}=3.89, p<0.031\right)$ but were comparable with $\mathrm{hTau}^{-1-} \mathrm{tTA}^{+1-}$ littermates (Fig. 6C). With 4 weeks of suppression, all rT2 genotypes also improved during visible $\left(F_{(4,132)}=87.15, p<0.0001\right)$ and hidden $\left(F_{(3,99)}=18.28, p<\right.$ $0.0001)$ training with no differences between genotypes (Fig. $6 D, E)$. All rT2 genotypes also exhibited search bias in probe trials: $\mathrm{hTau}^{-1-} \mathrm{tTA}^{-1-}\left(F_{(3,44)}=17.41, p<0.0001\right), \mathrm{hTau}^{-1-} \mathrm{tTA}^{+/-}$ $\left(F_{(3,44)}=17.45, p<0.0001\right)$, and $\mathrm{hTau}^{+/-} \mathrm{tTA}^{+/-}\left(F_{(3,44)}=\right.$ 18.45, $p<0.0001$ ) (Fig. $6 F$ ). There was no difference in time spent in the target quadrant between rT2 genotypes (Fig. $6 F$ ).
In the 12 week suppression group, rT1 performance was comparable with $\mathrm{hTau}^{-1-} \mathrm{tTA}^{-1-}$ and $\mathrm{hTau}^{-1-} \mathrm{tTA}^{+1-}$ littermates in visible $\left(F_{(4,128)}=57.19, p<0.0001\right)$ and hidden $\left(F_{(3,96)}=\right.$ $32.32, p<0.0001$ ) training (Fig. $6 G, H)$. A main effect of genotype $\left(F_{(2,32)}=3.66, p=0.037\right)$ in hidden training arose due to slight differences on day 1 (Fig. 6H). All rT1 genotypes exhibited search bias in probe trials: $\mathrm{hTau}^{-1-} \mathrm{tTA}^{-1-}\left(F_{(3,44)}=17.71, p<\right.$ $0.0001), \mathrm{hTau}^{-1-} \mathrm{tTA}^{+/-}\left(F_{(3,44)}=12.35, p<0.0001\right)$, and $\mathrm{hTau}^{+/-} \mathrm{tTA}^{+/-}\left(F_{(3,44)}=12.94, p<0.0001\right)$ (Fig. 6I). No differences between $\mathrm{rT} 1$ genotypes were detected in terms of time spent in the target quadrant (Fig. $6 I$ ). rT2 mice suppressed for 12 weeks also improved as visible $\left(F_{(4,132)}=100.9, p<0.0001\right)$ and hidden $\left(F_{(3,99)}=33.3, p<0.0001\right)$ training progressed (Fig. $6 \mathrm{~J}, \mathrm{~K})$. A main effect of genotype $\left(F_{(2,33)}=3.29, p=0.050\right)$ arose due to slight differences between genotypes on day 1 of visible training (Fig. $6 \mathrm{~J}$ ). All rT2 genotypes also exhibited search bias in probe trials: $\mathrm{hTau}^{-1-} \mathrm{tTA}^{-1-}\left(F_{(3,44)}=33.1, \mathrm{p}<0.0001\right)$, $\mathrm{hTau}^{-1-} \mathrm{tTA}^{+/-}\left(F_{(3,44)}=18.82, p<0.0001\right)$, and $\mathrm{hTau}^{+/-}$ $\mathrm{tTA}^{+/-}\left(F_{(3,44)}=15.33, p<0.0001\right)$ (Fig. 6L). There was no difference in time spent in the target quadrant between rT2 genotypes (Fig. $6 \mathrm{~L}$ ). Together, these data show that developmental transgene suppression prevented the cognitive impairments in rT1 mice.

\section{Higher ratios of MT-bound to -unbound 4R NM hTau than P301L hTau}

If developmental overexpression of $4 \mathrm{R}$ tau is toxic, why are abnormal molecular phenotypes and cognitive dysfunction present only in rT1 mice and not also rT2? A major consequence of the P301L mutation, which lies in tau's second MT binding domain encoded by the alternatively spliced exon 10, is a reduction in the ability of tau to bind MTs (Hong et al., 
A

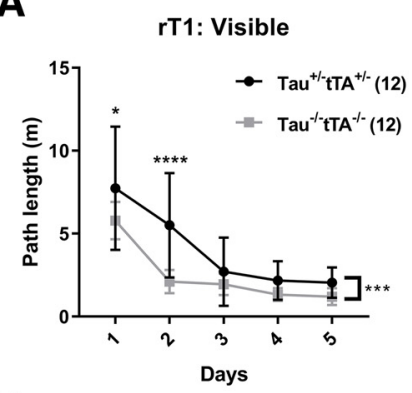

D

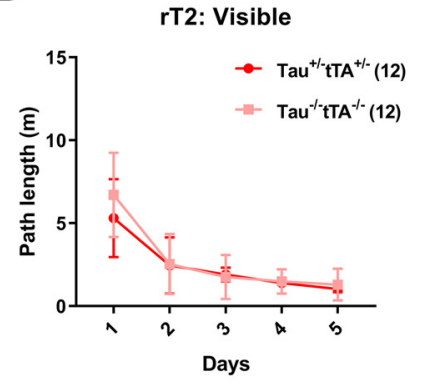

B

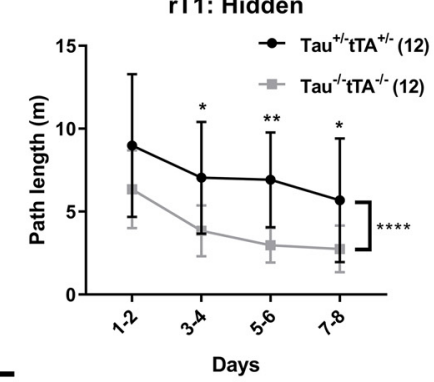

E

rT2: Hidden

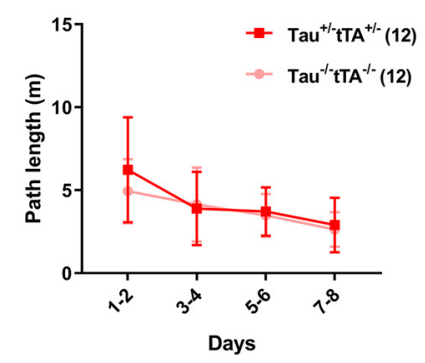

C rT1: Probe

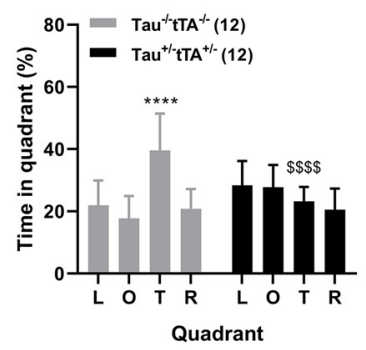

$\mathbf{F}$

rT2: Probe

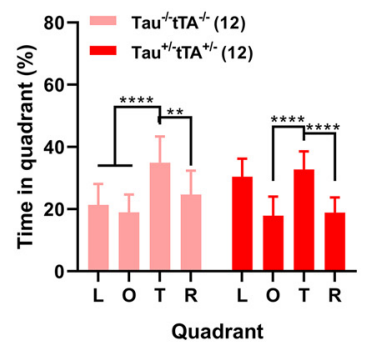

\section{Developmental suppression with DOX}

G

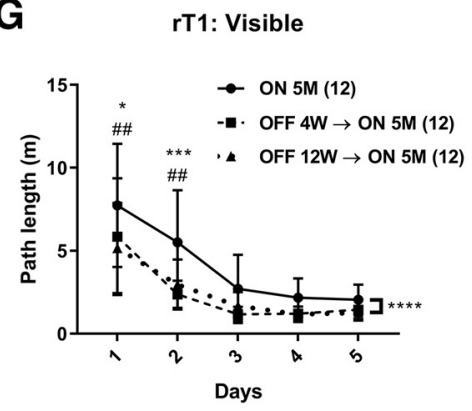

J

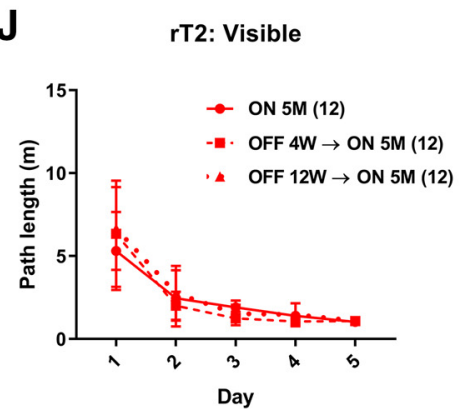

H

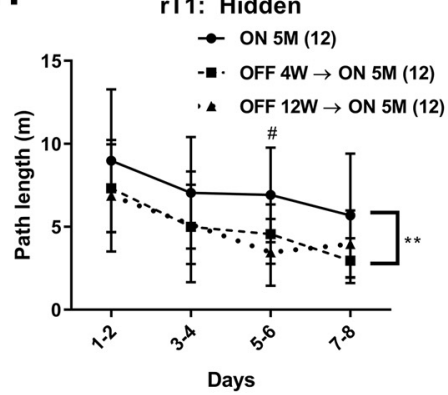

K

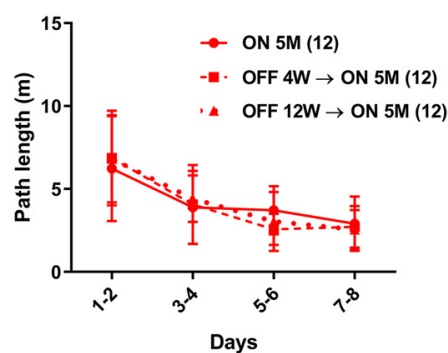

I

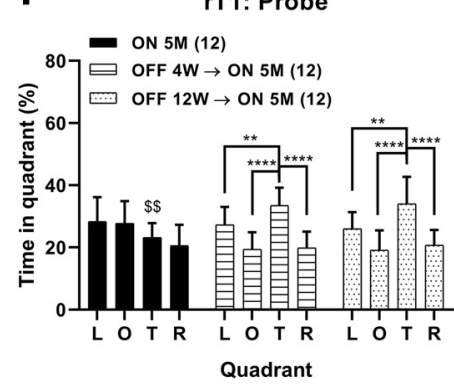

L

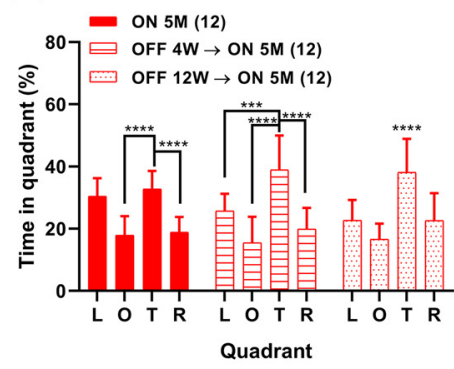

Figure 5. Cognitive deficits in rT1 are prevented with developmental suppression. The Morris Water Maze was used to measure cognitive function in rT1 and rT2 mice. Five-month-old rT1 mice exhibit learning deficits in visible-platform training $(\boldsymbol{A})$, hidden-platform training $(\boldsymbol{B})$, and spatial reference memory during probe trials $(\boldsymbol{C})$. Probe trial data show time spent in left $(\mathrm{L})$, opposite $(0)$, target $(\mathrm{T})$, and right $(\mathrm{R})$ quadrants to assess search bias. $\boldsymbol{D}-\boldsymbol{F}$, Five-month-old rT2 mice are indistinguishable from nontransgenic littermates in all trials. With D0X-mediated suppression of $\mathrm{hTau}$ during the first 4 or 12 weeks of life, followed by hTau expression for 5 months ( $0 F F 4 W \rightarrow 0 N 5 M$ and $0 F F 12 W \rightarrow 0 N 5 M$, respectively), rT1 performance improves in all aspects of the task compared with 5-month-old animals (ON 5M) (G-I). * Differences between ON 5M and OFF 4W groups. "Differences between ON 5M and OFF $12 \mathrm{~W}$ groups (G,H). DOX treatment had no effect on rT2 cognition $(J-L)$. For all probe data: * Tests for search bias. ${ }^{\$}$ Differences in time spent in target quadrant $(T)$ between groups. $n$ values are in parentheses. Graphs represent group mean \pm SD. All probe data represent the average values for three probe trials. Symbols to right of visible and hidden graphs represent main effect of genotype $(\boldsymbol{A}-\boldsymbol{F})$ or D0X treatment $(\mathbf{G}-\boldsymbol{L}) .{ }^{*} p<0.05,{ }^{\#} p<0.05,{ }^{* *} p<$ $0.01,{ }^{\# \#} p<0.01,{ }^{\$ \$} p<0.01,{ }^{* * *} p<0.001,{ }^{\$ \$ \$ \$} p<0.0001,{ }^{* * * *} p<0.0001$.

1998). We hypothesized that this loss of function conferred by the pathogenic $\mathrm{P} 301 \mathrm{~L}$ mutation is protective against molecular and cognitive phenotypes associated with 4R NM hTau.

To quantify MT-bound versus - unbound hTau in 8-week-old rT1 and rT2, we isolated MTs and MAPs from forebrains (Fig.
7A). P301L hTau was found to be more abundant in the cytosol $\left(t_{(12)}=5.60, p=0.0001\right)$, whereas NM hTau was more abundant in the MT/MAP pellet $\left(t_{(12)}=5.21, p=0.0002\right)($ Fig. $7 B, C)$. The mean ratios of MT-bound to -unbound hTau were 1.46 for NM and 0.70 for P301L hTau, demonstrating that 4R NM hTau binds MTs significantly stronger than P301L hTau. This also suggests 


\section{4-week suppression}

A

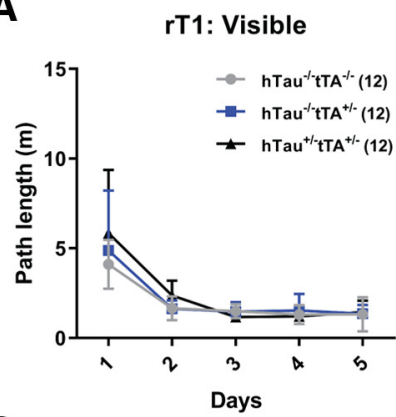

D

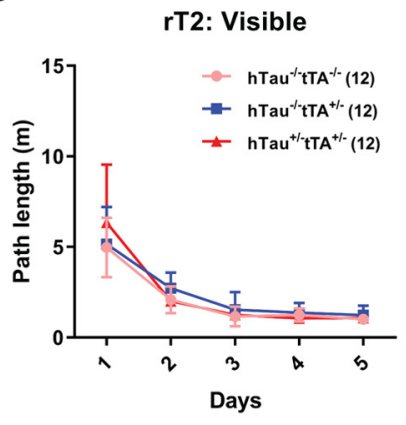

B

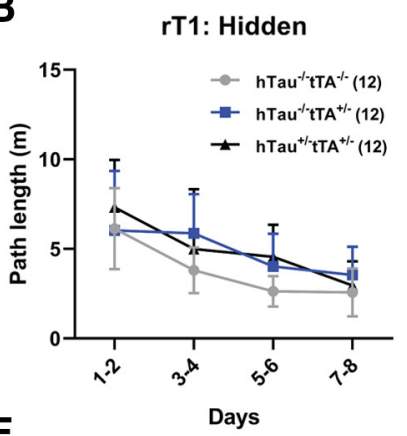

E

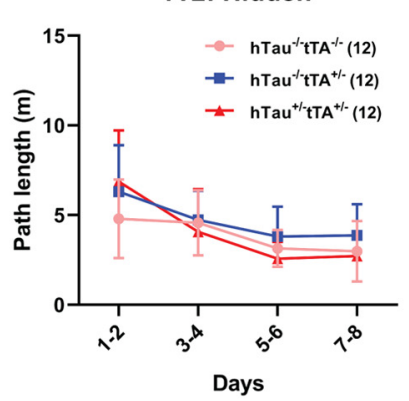

C

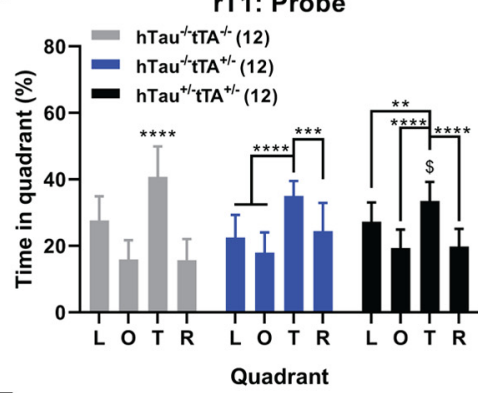

$\mathbf{F}$

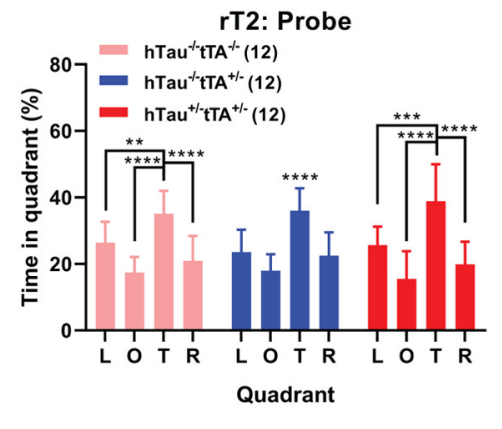

G

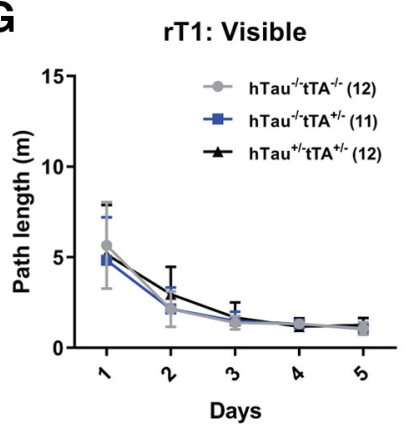

J

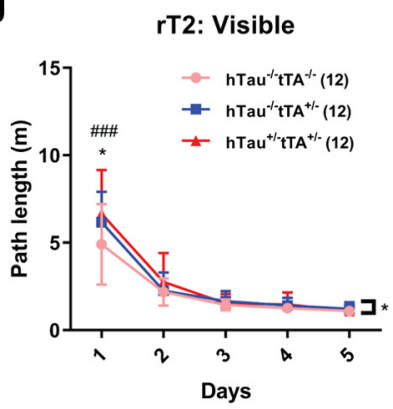

12-week suppression

H rT1: Hidden

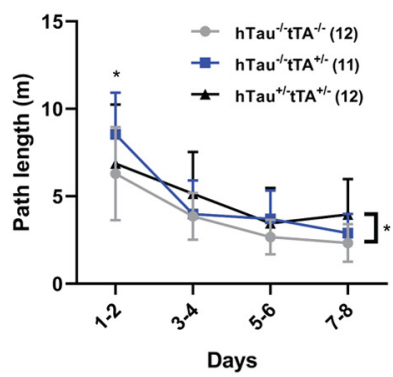

K

rT2: Hidden

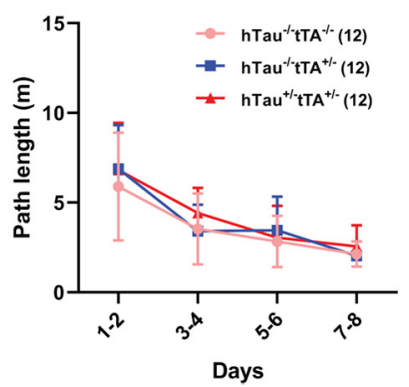

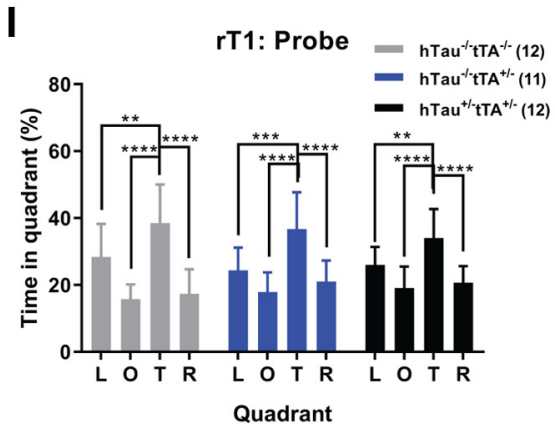

$\mathbf{L}$

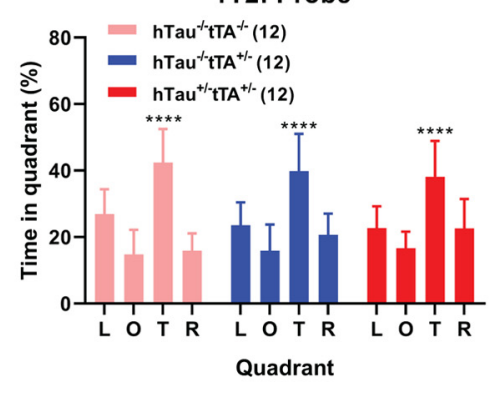

Figure 6. Cognitive performance in suppressed rT1 and rT2 compared with control genotypes. $\mathrm{rT1}$ and rT2 performance was comparable with hTau ${ }^{-1-} \mathrm{tTA}^{-1-}$ and hTau ${ }^{-1-} \mathrm{tTA}^{+/-}$

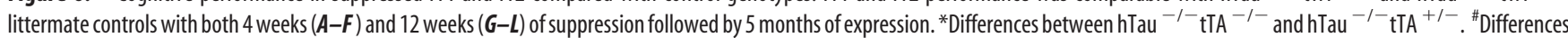
between $\mathrm{hTau}^{-1-} \mathrm{tTA}^{-1-}$ and hTau ${ }^{+/-} \mathrm{tTA}^{+/-}(\boldsymbol{H}, \boldsymbol{J})$. For all probe data: ${ }^{*}$ Tests for search bias. ${ }^{5}$ Differences in time spent in target quadrant $(\mathrm{T})$ between groups. $n$ values are in parentheses. Graphs represent group mean \pm SD. All probe data represent the average values for three probe trials. Symbols to right of visible and hidden graphs represent main effect of genotype. ${ }^{*} p<0.05$. $\$_{p}<0.05,{ }^{* *} p<0.01,{ }^{* * *} p<0.001,{ }^{* * * *} p<0.0001,{ }^{\# \# \#} p<0.001$.

that reduced MT binding of P301L hTau protects against abnormal molecular and cognitive phenotypes.

\section{Mitochondrial abnormalities and oxidative stress in rT1}

Overexpression of tau is known to cause a disruption of mitochondrial fission and fusion dynamics (Li et al., 2016), which contributes to neurodevelopmental disorders (Waterham et al., 2007). Therefore, we examined mitochondrial length in primary hippocampal neurons derived from P0 rT1 and rT2 mice. Active hTau expression was confirmed in our cultures (data not shown), which were transfected with an EGFP construct to identify axons and a mitochondria-specific RFP construct to visualize mito- 
A

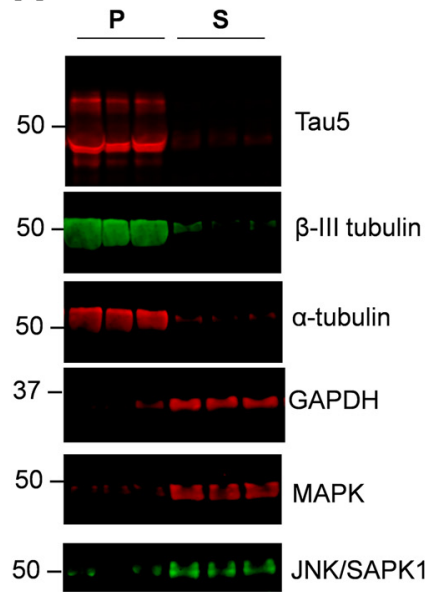

B

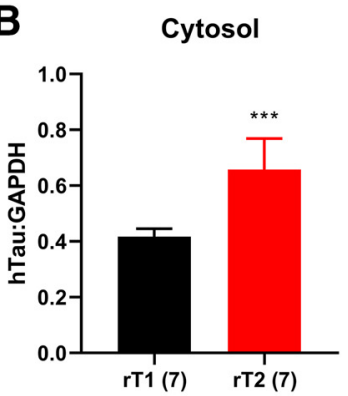

C MT/MAP fraction

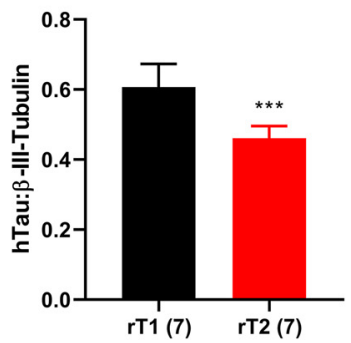

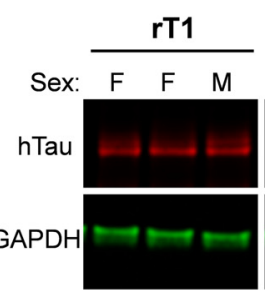

rT2
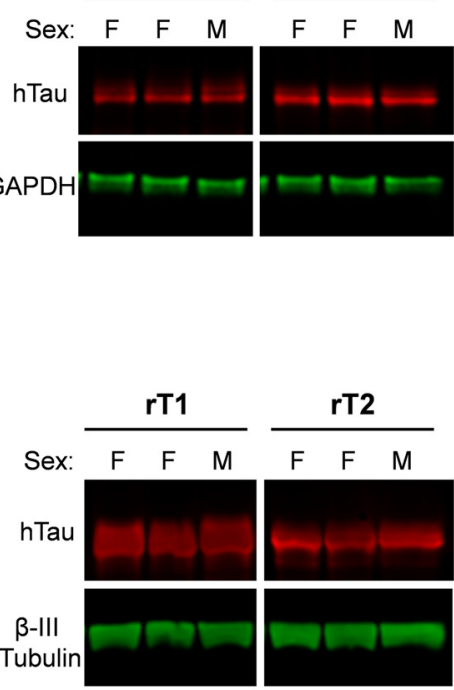

rT2

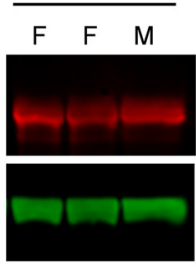

Figure 7. 4R NM hTau binds MTs more strongly than P301L hTau. $A$, Validation of protocol to isolate MTs and MAPs in the pellet (P), leaving cytosolic elements in the supernatant (S) with molecular weight in kDa indicated on the left. The cytosolic fractions $(\boldsymbol{B})$ and MT/MAP fractions $(\boldsymbol{C})$ were run through SDS-PAGE and immunolabeled with $\mathrm{hTau}, \mathrm{GAPDH}$, and $\beta$-III tubulin antibodies. Right, Representative images with samples from both female (F) and male (M) mice. Proteins were run on $10.5 \%-14 \%$ gels. Fluorescent signal from Western blots was quantified by densitometry, and values represent averages of two separate experiments (left). Graphs represent group mean \pm SD. $n$ values are in parentheses. ${ }^{* * *} p<0.001$.

A

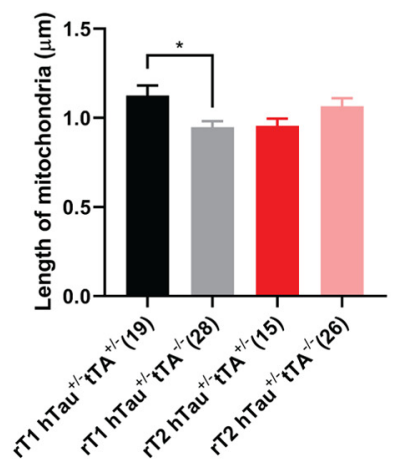

B

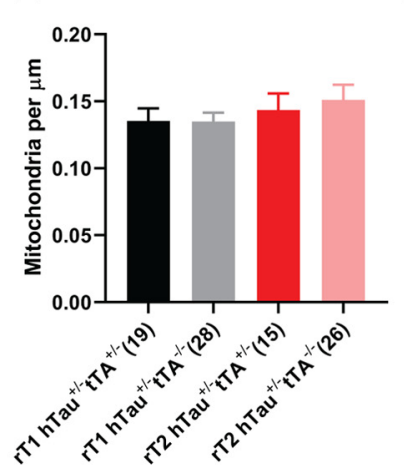

C

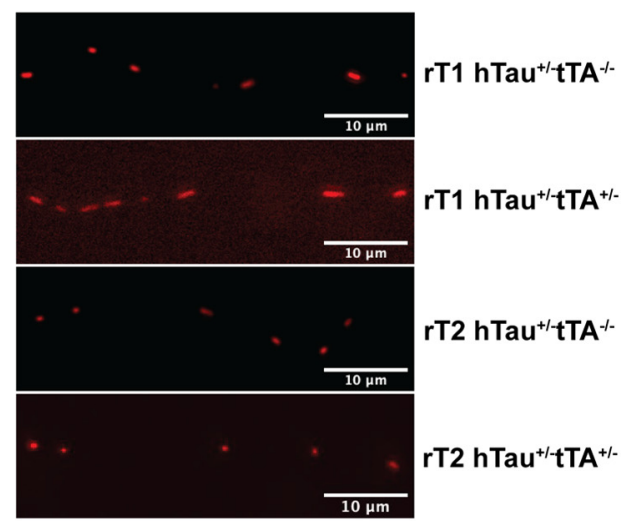

Figure 8. Elongated mitochondria with no change in density in rT1 hippocampal axons. The length of mitochondria $(\boldsymbol{A})$ and density of mitochondria $(\boldsymbol{B})$ were measured in primary hippocampal neurons derived from rT1 and rT2 postnatal day 0 pups. hTau-only $\left(\mathrm{hTau}^{+/-} \mathrm{tTA}^{-1-}\right.$ ) controls were included for comparison. The number of axons in which mitochondria were counted and measured are shown in parentheses for each group. Neurons were taken from a total of $10 \mathrm{rT}^{\mathrm{hTau}}{ }^{+/-} \mathrm{tTA}^{+/-}, 7 \mathrm{rT1} \mathrm{hTau}^{+/-} \mathrm{tTA}^{-1-}, 7 \mathrm{rT2}_{\mathrm{hTau}}^{+/-} \mathrm{tTA}^{+/-}$, and $4 \mathrm{rT2} \mathrm{hTau}^{+/-} \mathrm{tTA}^{-1-}$ mice. C, Representative images of axonal mitochondria in hippocampal neurons. Graphs represent group mean \pm SEM. ${ }^{*} p<0.05$.

chondria within the axon, as done previously (Vossel et al., 2015). We found that while there was no difference in mitochondria density (Fig. 8B), mitochondria were longer in axons from rT1 $\left(\mathrm{hTau}^{+/-} \mathrm{tTA}^{+/-}\right.$) than from control ( $\mathrm{hTau}^{+/-} \mathrm{tTA}^{-/-}$) neurons $(H=10.9, p=0.012)$, whereas there was no difference in mitochondrial length between rT2 and control neurons (Fig. 8A, C). We also observed no differences in the percentages of moving mitochondria or the velocity of mobile mitochondria between groups (data not shown). Although we did not observe effects on mitochondrial transport, these findings are consistent with developmental pathogenicity of 4R NM hTau, and further suggest that impaired mitochondrial dynamics are part of that pathogenic pathway.

Disruptions in mitochondrial dynamics have been shown to be linked to oxidative stress (DuBoff et al., 2012). Therefore, we assessed oxidative damage to DNA and RNA using the marker 8-hydroxy-2'-deoxyguanosine (8OHdG) in 2-month-old rT1, rT2, and littermate controls. We found that $8 \mathrm{OHdG}$ staining was more intense in rT1 than for other samples (Fig. 9A). We also quantified the signal intensity and found that, indeed, oxidative stress was higher in rT1 than rT2 in the CA1 region of the hippocampus $\left(F_{(1,30)}=29.38, p<0.0001\right)$ and in cortex $\left(F_{(1,30)}=\right.$ $11.11, p=0.0023$ ) (Fig. 9B, $C$ ). Interestingly, oxidative stress in the dentate gyrus was highest in nontransgenic littermates $\left(F_{(2,30)}\right.$ $=16.93, p<0.0001$ ) (Fig. 9D), which may be explained by a requirement for high levels of ROS in the regulation of adult neurogenesis (Le Belle et al., 2011; Wilson et al., 2018). This suggests that tTA and hTau expression may contribute to redox imbalance in the dentate gyrus, which could have consequences for adult neurogenesis and therefore cognition. We note that the $8 \mathrm{OHdG}$ signal may represent not only nuclear and mitochondrial DNA, but also RNA. 


\section{A}

rT1

rT2

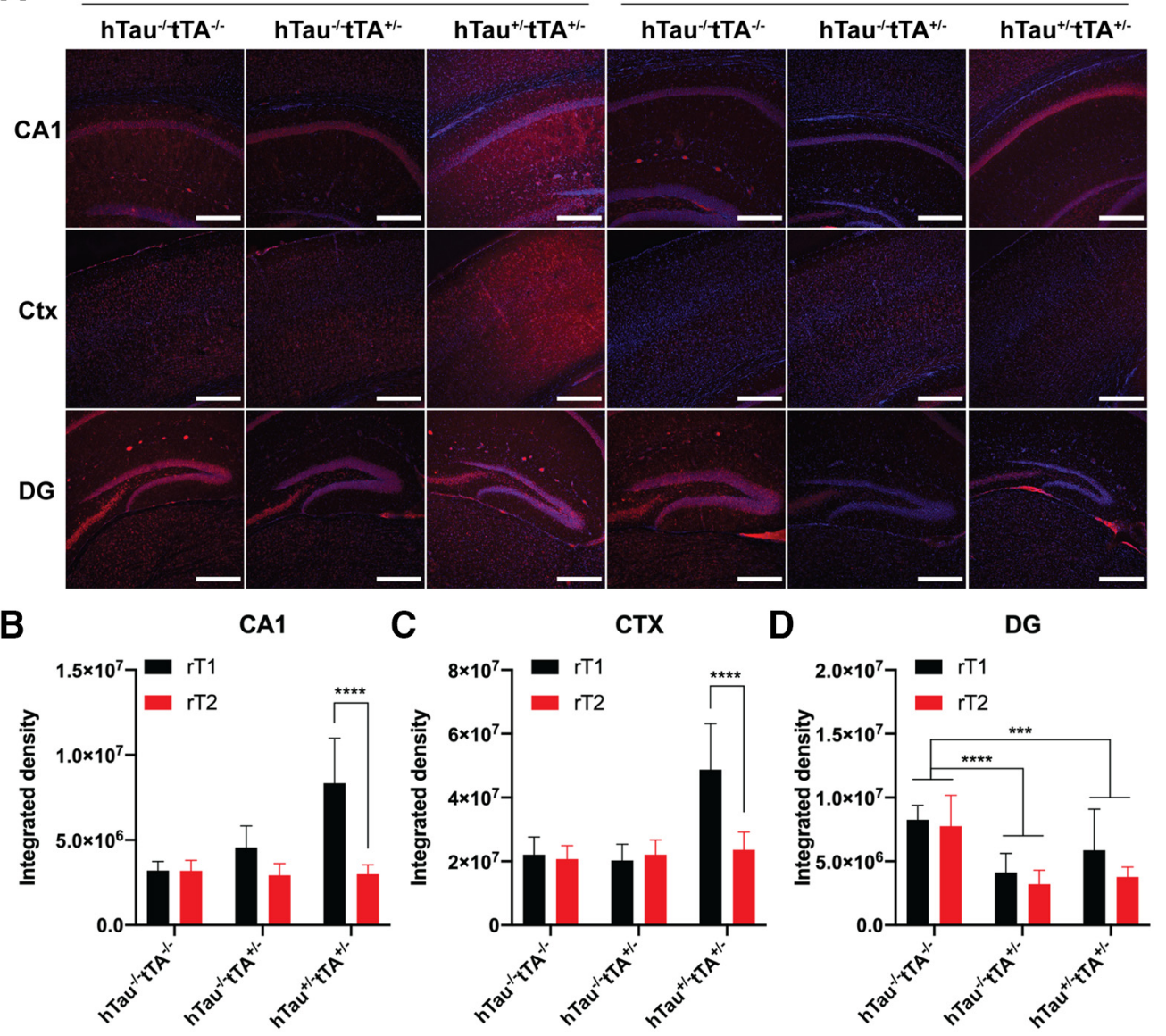

Figure 9. Elevated oxidative stress in 2 month rT1 brains. $A$, Representative images show 80HdG (red), a marker for oxidative damage to DNA and RNA, in 2-month-old rT1 and rT2 animals in addition to $\mathrm{hTau}^{-1-} \mathrm{tTA}^{-1-}$ and hTau ${ }^{-1-} \mathrm{tTA}^{+/-}$littermate controls. Images are shown for the three areas assessed: hippocampal CA1, somatomotor areas of cortex (Ctx), and dentate gyrus (DG). Blue represents DAPI. $\boldsymbol{B}-\boldsymbol{D}$, Quantification of intensity of the red signal in terms of integrated density to account for differences in ROI areas. $n=3$ males and $n=3$ females per group. Graphs represent group mean \pm SD. Scale bars, $500 \mu \mathrm{m} .{ }^{* * *} p<0.001,{ }^{* * * *} p<0.0001$.

\section{Reduced brain mass in postnatal $\mathrm{rT} 1$ mice}

Knowing that aberrantly elongated mitochondria in neurodevelopmental disorders are accompanied by microcephaly (Waterham et al., 2007), and that an excess of tau interferes with cell division, leading to aneuploidy and neuronal apoptosis (Bougé and Parmentier, 2016; Malmanche et al., 2017), we postulated that rT1 mice may have abnormal brain development. To test this, we simply weighed whole brains and compared brain mass of rT1, rT2, and littermates.

Our analysis of brain mass showed that rT1, rT2, and tTA mice had reduced brain mass compared with hTau ${ }^{-1-} \mathrm{tTA}^{-1-}$ and $\mathrm{hTau}^{+/-} \mathrm{tTA}^{-1-}$ controls $\left(F_{(3,251)}=45.15, p<0.0001\right)$, and that rT1 mice had reduced brain mass compared with rT2 $\left(F_{(1,251)}=19.27, p<0.0001\right.$; rT1 mean $=0.429 \mathrm{~g}, \mathrm{SD}=0.018$; rT2 mean $=0.443 \mathrm{~g}, \mathrm{SD}=0.021)$ (Fig. 10A). Despite the contribution of tTA-induced toxicity, 4R NM hTau was associated with a subtle reduction in brain mass compared with P301L hTau. This suggests that tTA-DNA binding interferes with normal brain development and that P301L hTau is protective from tTA toxicity whereas NM hTau is not. In addition, 4 weeks and, to a greater extent, 12 weeks of developmental suppression of hTau and tTA-DNA binding was associated with increased brain mass in $\operatorname{rT1}\left(F_{(2,46)}=17.67, p<0.0001\right)$, but had no effect on brain mass in rT2 mice (Fig. 10B). These results indicate that 4R NM hTau overexpression during postnatal development is associated with a subtle reduction in brain size compared with P301L hTau.

\section{Discussion}

The 30 different tauopathy mouse models harboring MAPTrelated modifications (https://www.alzforum.org/research-models) have extreme variability in their phenotypes, creating confusion in attempts to understand how the tau protein causes neurodegenerative diseases. Using novel genetically matched mouse lines, we sought to determine how the pathogenic P301L mutation affects tau biology in vivo. Surprisingly, we have identified a development-specific toxicity of 4R NM hTau, which undergoes abnormal regulation in young animals and eventually causes cognitive impairments. Strikingly, both the molecular and behavioral phenotypes associated with 4R NM hTau were lost with the P301L mutation.

We found that clearance of hTau was impaired in rT1 mice, underlying an elevation of steady-state levels. The half-life of $4 \mathrm{R}$ NM hTau was significantly longer than P301L hTau (Fig. 2; Table 3 ), and is comparable with a different tauopathy mouse model (Yamada et al., 2015). The hyperphosphorylation of NM hTau (Fig. 3) may explain its long half-life because phosphorylation of Ser396 and Ser404, elevated in rT1 mice, has been associated with impaired proteasome function (Poppek et al., 2006; Ren et al., 2007). The robust pSer202 phosphorylation of NM hTau (Figs. 3, 4) may be particularly important for regulating tau dynamics because this event primes tau for Ser396/404 phosphorylation ( $\mathrm{Li}$ and Paudel, 2006; Li et al., 2006). 
A

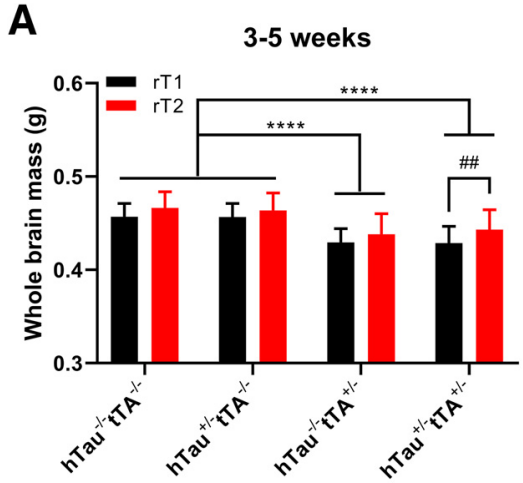

B

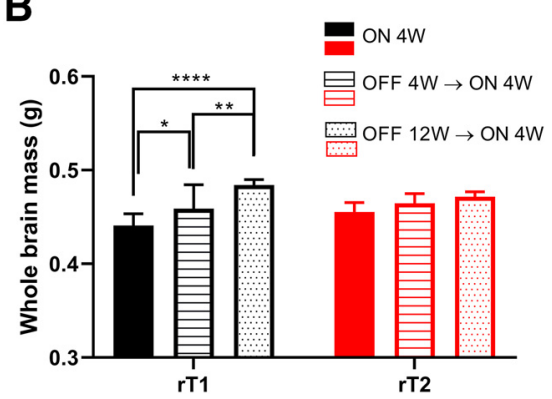

Figure 10. Reduced brain mass in postnatal rT1 mice. $\boldsymbol{A}$, Whole brains from $\mathrm{rT1}$, rT2, and littermates between the ages of 3 and 5 weeks were weighed $\left(\mathrm{rT} 1: n=27 \mathrm{hTau}^{-1-} \mathrm{tTA}^{-1-}, 35\right.$ $\mathrm{hTau}^{+/-} \mathrm{tTA}^{-1-}, 28 \mathrm{hTau}^{-1-} \mathrm{tTA}^{+/-}$, and $33 \mathrm{hTau}^{+/-} \mathrm{tTA}^{+/-} ; \mathrm{rT2}: n=33 \mathrm{hTau}^{-1-}$ $\mathrm{tTA}^{-1-}, 33 \mathrm{hTau}^{+1-} \mathrm{tTA}^{-1-}, 36 \mathrm{hTau}^{-1-} \mathrm{tTA}^{+1-}$, and $\left.34 \mathrm{hTau}^{+1-} \mathrm{tTA}^{+1-}\right)$. ${ }^{*}$ Differences between genotypes. "Differences between lines. $\boldsymbol{B}$, Brain mass was compared between 3 groups of Tau ${ }^{+/-} \mathrm{TTA}^{+/-} \mathrm{rT1}$ and $\mathrm{rT2}$ : 4-week-old animals (0N 4W, $n=12 \mathrm{rT1}$ and $7 \mathrm{rT2}$ ), hTau suppressed for 4 weeks followed by expression for 4 weeks ( $0 F F 4 \mathrm{~W} \rightarrow 0 \mathrm{~N} 4 \mathrm{~W}, n=9 \mathrm{rT1}$ and 10 rT2), and 12 weeks of suppression followed by 4 weeks of expression (OFF $12 \mathrm{~W} \rightarrow 0 \mathrm{~N}$ $4 \mathrm{~W}, n=6 \mathrm{rT1}$ and $8 \mathrm{rT2}$ ). Graphs represent group mean \pm SD. ${ }^{*} p<0.05,{ }^{* *} p<0.01,{ }^{* \#} p<$ $0.01,{ }^{* * * *} p<0.0001$.

Patterns of tau phosphorylation during normal rodent development suggest that NM hTau remains aberrantly hyperphosphorylated. Many sites on tau, including Ser202 and Ser404, are highly phosphorylated early on and slowly decline thereafter (Yu et al., 2009). P301L but not NM hTau follows this normal developmental pattern, and NM hTau remains hyperphosphorylated by $4-5$ weeks of age (Figs. 3,4 ), strongly suggesting developmental dysregulation of hTau in rT1 brains. These findings parallel those of other transgenic lines in which developmental mislocalization (Brion et al., 1999) and hyperphosphorylation (Spittaels et al., 1999; Probst et al., 2000; Terwel et al., 2005) of overexpressed NM hTau are observed. In particular, a nonprogressive developmental phenotype associated with NM but not P301L hTau was previously published (Hoover et al., 2010), suggesting that a similar pathogenic process occurs in $\mathrm{rT} 1$ and $\mathrm{rTg} 21221$ (rTgWT) lines. We previously used genetically matched transgenic lines to demonstrate that the level of hTau expression positively correlates with the severity of histopathology (Gamache et al., 2019). Similarly, our current results show elevated tau phosphorylation in $\mathrm{rT} 1$, which overexpress hTau by approximately twofold compared with rT2 (Fig. 1E). Future studies on tau histopathology in rT1 and rT2 will clarify whether the level of hTau overexpression, regardless of any disease-linked mutations, is the determining factor in the severity of histopathology.

The rise in 4R NM hTau levels in $\mathrm{rT} 1$ brains, in addition to the 12.6-fold overexpression of human relative to endogenous mouse tau, causes massive overrepresentation of $4 \mathrm{R}$ tau isoforms.
Most MAPT mutations that alter splicing in human tauopathies increase the 4R:3R ratio (Arendt et al., 2016), leading 4R tau to be labeled as a toxic variant (Schoch et al., 2016). Therefore, it is no surprise that 4R NM hTau exhibits an abnormal molecular phenotype, especially when considering the importance of splice variant regulation during development. In both rodent (McMillan et al., 2008) and human (Hefti et al., 2018) fetal brain, 3R tau isoforms predominate. With a threefold lower MT binding capacity than 4R tau (Goode et al., 2000), 3R tau facilitates MT dynamics necessary for developmental processes, such as neurite outgrowth (Shea and Beermann, 1994; Bunker et al., 2004). The dramatic imbalance of $3 \mathrm{R}$ and $4 \mathrm{R}$ tau in postnatal $\mathrm{rT} 1$, during which newborn neurons require dynamic rather than stable MTs, likely contributes to the abnormal rT1 phenotype.

Counterintuitively, yet consistent with our other findings, $\mathrm{rT1}$ and not rT2 mice were cognitively impaired in the Morris Water Maze at 5 months of age (Fig. 5). Hyperphosphorylated tau, when mislocalized to dendritic spines, can cause deficits in postsynaptic transmission due to internalization of postsynaptic AMPA receptors (Hoover et al., 2010). Phosphorylation at the sites we have reported here is required both for tau mislocalization to the postsynapse and for tau-induced reduction of AMPA receptors (Teravskis et al., 2019). Our observations of hyperphosphorylated 4R NM hTau within PSD-95-enriched fractions (Fig. 3C,D) suggest that a reduction in postsynaptic signaling underlies $\mathrm{rT} 1$ cognitive deficits.

Disruption of mitochondrial dynamics and oxidative stress (Figs. 8, 9) may be related to the subtle deficiencies in brain mass (Fig. 10). Tau overexpression in other experimental models is associated with MT elongation (DuBoff et al., 2012) via increased expression of fusion proteins (Li et al., 2016). Impaired fission is linked to neurodevelopmental abnormalities in humans (Waterham et al., 2007) and rodents (Ishihara et al., 2009), as neural stem cell fate requires a switch from elongated to fragmented mitochondria (Khacho et al., 2016). Our findings suggest that 4R $\mathrm{NM} \mathrm{hTau}$ is associated with a failure of mitochondria to switch to a fragmented phenotype, disrupting stem cell fate decisions. Although we do not show the relative timing of these events, previous studies suggest that oxidative stress associated with mitochondrial dysfunction occurs upstream of tau hyperphosphorylation via imbalanced activation of kinases and phosphatases (Melov et al., 2007; Su et al., 2010). Together, our results are consistent with a neurodevelopmental failure, rather than a progressive neurodegenerative phenotype.

Developmental suppression temporarily reduced NM hTau levels and phosphorylation (Fig. 4) and prevented cognitive deficits in rT1 (Fig. 5G-I, Fig. 6A-C, G-I). Four weeks had essentially the same effects as 12 weeks of suppression, suggesting that $4 \mathrm{R}$ NM hTau overexpression specifically interferes with developmental milestones during the first 4 weeks of life, such as peaks in brain growth, synaptic density, and myelination rate (Semple et al., 2013). Importantly, DOX treatment did not lower hTau after 8 weeks of post-suppression expression (Fig. 4), establishing that amelioration of the phenotype is not due to reduction of hTau per se. Furthermore, despite a moderate rise in NM hTau levels and phosphorylation after suppression (Fig. 4), rT1 cognition remained intact, indicating that those molecular phenotypes are harmful during the first 4 weeks but not afterward. Because hTau expression and tTA toxicity are intrinsically linked in our models, we cannot exclude the possibility that tTA-driven toxicity and suppression of tTA-DNA binding contribute to the abnormal rT1 phenotype and amelioration of that phenotype, respectively (Han et al., 2012). Further examination of the tTA mouse phe- 
notype in future studies may provide a mechanistic explanation for the specificity of these effects to $\mathrm{rT} 1 \mathrm{mice}$.

We found that 4R NM hTau bound MTs significantly more than P301L hTau (Fig. 7), suggesting that a function of the MT binding domain encoded by exon 10 is part of a pathogenic pathway in developing rT1 brains. Because we made this observation in 8-week-old mice, it is possible that stronger MT binding of NM compared with P301L hTau is downstream of other events. However, because of natural physiological differences between $4 \mathrm{R} \mathrm{NM}$ and P301L tau (Hong et al., 1998; Goode et al., 2000), we view strong MT binding as a pathological trigger rather than a downstream effect. In this context, it appears that the P301L mutation is protective. Future studies on aged $\mathrm{rT} 1$ and $\mathrm{rT} 2$ will determine whether pathogenicity of P301L hTau requires the unique milieu of the aging brain.

The developmental pathogenicity of 4R NM hTau we have uncovered may be relevant to a range of neurological conditions. Infantile tauopathies, which include neurodevelopmental conditions, such as hemimegalencephaly, ganglioglioma, and tuberous sclerosis, are characterized by upregulation and hyperphosphorylation of tau (Ohmi et al., 2009; Sarnat and Flores-Sarnat, 2015). Future experiments will determine whether the pathway we have identified may be involved in the pathogenesis of these diseases. Although our results strongly suggest a developmentspecific mechanism, the massive overexpression of $4 \mathrm{R}$ tau may exaggerate and accelerate the phenotype. Therefore, our results may be indicative of an event that occurs early in human disease yet slowly manifests over time, similar to what occurs in Huntington's disease (Wiatr et al., 2018).

In conclusion, genetic matching between transgenic mouse lines has allowed us to explore molecular and cognitive phenotypes associated with different forms of tau in a well-controlled manner, and to identify a pathogenic mechanism of $4 \mathrm{R} N \mathrm{NMTau}$ distinct from classical aging-related tauopathy. Future studies using a tTA line without the transgene INDEL mutation (Gamache et al., 2019) will clarify whether the phenotypes we observed here are due to hTau alone or in concert with other tTA-induced dysfunctions. It will also be useful to characterize phenotypes associated with other tau isoforms and expression patterns, and to use this system to test hypotheses concerning other diseaselinked mutations, truncated forms of tau, etc.

We believe our findings also highlight the importance of assaying the effects of transgenic proteins at appropriate stages in life, as the milieu of the infantile brain consists of an entirely different proteome than the aged brain (Emilsson et al., 2018; Yousefzadeh et al., 2018). This study is one example among others (Serra et al., 2006; Han et al., 2012; Helboe et al., 2017) demonstrating that the effects of transgenic proteins differ in mice at different times during their lifespan. Now that advances in techniques allow more precise characterization and manipulation of genomes of transgenic mice, models of neurodegenerative diseases can be held to higher standards. We hope that this type of work will improve translatability of therapies from mice to humans in clinical trials, and bring the field closer to solving the complex puzzle of tauopathies, such as Alzheimer's disease.

\section{References}

Adams SJ, Crook RJ, Deture M, Randle SJ, Innes AE, Yu XZ, Lin WL, Dugger BN, McBride M, Hutton M, Dickson DW, McGowan E (2009) Overexpression of wild-type murine tau results in progressive tauopathy and neurodegeneration. Am J Pathol 175:1598-1609.

Andorfer C, Acker CM, Kress Y, Hof PR, Duff K, Davies P (2005) Cell-cycle reentry and cell death in transgenic mice expressing nonmutant human tau isoforms. J Neurosci 25:5446-5454.
Arendt T, Stieler JT, Holzer M (2016) Tau and tauopathies. Brain Res Bull 126:238-292.

Benhelli-Mokrani H, Mansuroglu Z, Chauderlier A, Albaud B, Gentien D, Sommer S, Schirmer C, Laqueuvre L, Josse T, Buée L, Lefebvre B, Galas MC, Souès S, Bonnefoy E (2018) Genome-wide identification of genic and intergenic neuronal DNA regions bound by tau protein under physiological and stress conditions. Nucleic Acids Res 46:11405-11422.

Boekhoorn K, Terwel D, Biemans B, Borghgraef P, Wiegert O, Ramakers GJ, de Vos K, Krugers H, Tomiyama T, Mori H, Joels M, van Leuven F, Lucassen PJ (2006) Improved long-term potentiation and memory in young tau-P301L transgenic mice before onset of hyperphosphorylation and tauopathy. J Neurosci 26:3514-3523.

Bougé AL, Parmentier ML (2016) Tau excess impairs mitosis and kinesin-5 function, leading to aneuploidy and cell death. Dis Model Mech 9:307-319.

Brion JP, Tremp G, Octave JN (1999) Transgenic expression of the shortest human tau affects its compartmentalization and its phosphorylation as in the pretangle stage of Alzheimer's disease. Am J Pathol 154:255-270.

Bunker JM, Wilson L, Jordan MA, Feinstein SC (2004) Modulation of microtubule dynamics by tau in living cells: implications for development and neurodegeneration. Mol Biol Cell 15:2720-2728.

Caceres A, Kosik KS (1990) Inhibition of neurite polarity by tau antisense oligonucleotides in primary cerebellar neurons. Nature 343:461-463.

de Calignon A, Polydoro M, Suárez-Calvet M, William C, Adamowicz DH, Kopeikina KJ, Pitstick R, Sahara N, Ashe KH, Carlson GA, Spires-Jones TL, Hyman BT (2012) Propagation of tau pathology in a model of early Alzheimer's disease. Neuron 73:685-697.

Dixit R, Ross JL, Goldman YE, Holzbaur EL (2008) Differential regulation of dynein and kinesin motor proteins by tau. Science 319:1086-1089.

DuBoff B, Götz J, Feany MB (2012) Tau promotes neurodegeneration via DRP1 mislocalization in vivo. Neuron 75:618-632.

Emilsson V, Ilkov M, Lamb JR, Finkel N, Gudmundsson EF, Pitts R, Hoover H, Gudmundsdottir V, Horman SR, Aspelund T, Shu L, Trifonov V, Sigurdsson S, Manolescu A, Zhu J, Olafsson Ö, Jakobsdottir J, Lesley SA, To J, Zhang J, et al. (2018) Co-regulatory networks of human serum proteins link genetics to disease. Science 361:769-773.

Forman MS, Lal D, Zhang B, Dabir DV, Swanson E, Lee VM, Trojanowski JQ (2005) Transgenic mouse model of tau pathology in astrocytes leading to nervous system degeneration. J Neurosci 25:3539-3550.

Gamache J, Benzow K, Forster C, Kemper L, Hlynialuk C, Furrow E, Ashe KH, Koob MD (2019) Factors other than hTau overexpression that contribute to tauopathy-like phenotype in $\mathrm{rTg} 4510$ mice. Nat Commun 10: 2479.

Gilley J, Seereeram A, Ando K, Mosely S, Andrews S, Kerschensteiner M, Misgeld T, Brion JP, Anderton B, Hanger DP, Coleman MP (2012) Agedependent axonal transport and locomotor changes and tau hypophosphorylation in a "P301L" tau knockin mouse. Neurobiol Aging 33: 621.e1-621.e15.

Goode BL, Chau M, Denis PE, Feinstein SC (2000) Structural and functional differences between 3-repeat and 4-repeat tau isoforms: implications for normal tau function and the onset of neurodegenerative disease. J Biol Chem 275:38182-38189.

Goodwin LO, Splinter E, Davis TL, Urban R, He H, Braun RE, Chesler EJ, Kumar V, van Min M, Ndukum J, Philip VM, Reinholdt LG, Svenson K, White JK, Sasner M, Lutz C, Murray SA (2019) Large-scale discovery of mouse transgenic integration sites reveals frequent structural variation and insertional mutagenesis. Genome Res 29:494-505.

Götz J, Probst A, Spillantini MG, Schäfer T, Jakes R, Bürki K, Goedert M (1995) Somatodendritic localization and hyperphosphorylation of tau protein in transgenic mice expressing the longest human brain tau isoform. EMBO J 14:1304-1313.

Han HJ, Allen CC, Buchovecky CM, Yetman MJ, Born HA, Marin MA, Rodgers SP, Song BJ, Lu HC, Justice MJ, Probst FJ, Jankowsky JL (2012) Strain background influences neurotoxicity and behavioral abnormalities in mice expressing the tetracycline transactivator. J Neurosci 32:1057410586.

Hanemaaijer R, Ginzburg I (1991) Involvement of mature tau isoforms in the stabilization of neurites in PC12 cells. J Neurosci Res 30:163-171.

Hefti MM, Farrell K, Kim S, Bowles KR, Fowkes ME, Raj T, Crary JF (2018) High-resolution temporal and regional mapping of MAPT expression and splicing in human brain development. PLoS One 13:e0195771.

Helboe L, Egebjerg J, Barkholt P, Volbracht C (2017) Early depletion of CA1 
neurons and late neurodegeneration in a mouse tauopathy model. Brain Res 1665:22-35.

Higuchi M, Ishihara T, Zhang B, Hong M, Andreadis A, Trojanowski J, Lee VM (2002) Transgenic mouse model of tauopathies with glial pathology and nervous system degeneration. Neuron 35:433-446.

Hong M, Zhukareva V, Vogelsberg-Ragaglia V, Wszolek Z, Reed L, Miller BI, Geschwind DH, Bird TD, McKeel D, Goate A, Morris JC, Wilhelmsen KC, Schellenberg GD, Trojanowski JQ, Lee VM (1998) Mutation-specific functional impairments in distinct tau isoforms of hereditary FTDP-17. Science 282:1914-1917.

Hoover BR, Reed MN, Su J, Penrod RD, Kotilinek LA, Grant MK, Pitstick R, Carlson GA, Lanier LM, Yuan LL, Ashe KH, Liao D (2010) Tau mislocalization to dendritic spines mediates synaptic dysfunction independently of neurodegeneration. Neuron 68:1067-1081.

Ishihara N, Nomura M, Jofuku A, Kato H, Suzuki SO, Masuda K, Otera H, Nakanishi Y, Nonaka I, Goto Y, Taguchi N, Morinaga H, Maeda M, Takayanagi R, Yokota S, Mihara K (2009) Mitochondrial fission factor Drp1 is essential for embryonic development and synapse formation in mice. Nat Cell Biol 11:958-966.

Ishihara T, Hong M, Zhang B, Nakagawa Y, Lee MK, Trojanowski JQ, Lee VM (1999) Age-dependent emergence and progression of a tauopathy in transgenic mice overexpressing the shortest human tau isoform. Neuron 24:751-762.

Ishihara T, Zhang B, Higuchi M, Yoshiyama Y, Trojanowski JQ, Lee VM (2001) Age-dependent induction of congophilic neurofibrillary tau inclusions in tau transgenic mice. Am J Pathol 158:555-562.

Ittner LM, Ke YD, Delerue F, Bi M, Gladbach A, van Eersel J, Wölfing H, Chieng BC, Christie MJ, Napier IA, Eckert A, Staufenbiel M, Hardeman E, Götz J (2010) Dendritic function of tau mediates amyloid-beta toxicity in Alzheimer's disease mouse models. Cell 142:387-397.

Khacho M, Clark A, Svoboda DS, Azzi J, MacLaurin JG, Meghaizel C, Sesaki H, Lagace DC, Germain M, Harper ME, Park DS, Slack RS (2016) Mitochondrial dynamics impacts stem cell identity and fate decisions by regulating a nuclear transcriptional program. Cell Stem Cell 19:232-247.

Kimura T, Fukuda T, Sahara N, Yamashita S, Murayama M, Mizoroki T, Yoshiike Y, Lee B, Sotiropoulos I, Maeda S, Takashima A (2010) Aggregation of detergent-insoluble tau is involved in neuronal loss but not in synaptic loss. J Biol Chem 285:38692-38699.

Kuznetsov SA, Rodionov VI, Gelfand VI, Rosenblat VA (1981) Purification of high-Mr microtubule proteins MAP1 and MAP2. FEBS Lett 135:237240.

Le Belle JE, Orozco NM, Paucar AA, Saxe JP, Mottahedeh J, Pyle AD, Wu H, Kornblum HI (2011) Proliferative neural stem cells have high endogenous ROS levels that regulate self-renewal and neurogenesis in a PI3K/ Akt-dependent manner. Cell Stem Cell 8:59-71.

Lewis J, McGowan E, Rockwood J, Melrose H, Nacharaju P, Van Slegtenhorst M, Gwinn-Hardy K, Paul Murphy M, Baker M, Yu X, Duff K, Hardy J, Corral A, Lin WL, Yen SH, Dickson DW, Davies P, Hutton M (2000) Neurofibrillary tangles, amyotrophy and progressive motor disturbance in mice expressing mutant (P301L) tau protein. Nat Genet 25:402-405.

Li T, Paudel HK (2006) Glycogen synthase kinase 3beta phosphorylates Alzheimer's disease-specific Ser396 of microtubule-associated protein tau by a sequential mechanism. Biochemistry 45:3125-3133.

Li T, Hawkes C, Qureshi HY, Kar S, Paudel HK (2006) Cyclin-dependent protein kinase 5 primes microtubule-associated protein tau sitespecifically for glycogen synthase kinase 3beta. Biochemistry 45:31343145.

Li XC, Hu Y, Wang ZH, Luo Y, Zhang Y, Liu XP, Feng Q, Wang Q, Ye K, Liu GP, Wang JZ (2016) Human wild-type full-length tau accumulation disrupts mitochondrial dynamics and the functions via increasing mitofusins. Sci Rep 6:24756.

Liu C, Götz J (2013) Profiling murine tau with 0N, 1N and 2N isoformspecific antibodies in brain and peripheral organs reveals distinct subcellular localization, with the $1 \mathrm{~N}$ isoform being enriched in the nucleus. PLoS One 8:e84849.

Lois C, Hong EJ, Pease S, Brown EJ, Baltimore D (2002) Germline transmission and tissue-specific expression of transgenes delivered by lentiviral vectors. Science 295:868-872.

Malmanche N, Dourlen P, Gistelinck M, Demiautte F, Link N, Dupont C, Vanden Broeck L, Werkmeister E, Amouyel P, Bongiovanni A, Bauderlique H, Moechars D, Royou A, Bellen HJ, Lafont F, Callaerts P, Lambert JC, Dermaut B (2017) Developmental expression of 4-repeat-tau in- duces neuronal aneuploidy in Drosophila tauopathy models. Sci Rep 7:40764.

Mayford M, Bach ME, Huang YY, Wang L, Hawkins RD, Kandel ER (1996) Control of memory formation through regulated expression of a CaMKII transgene. Science 274:1678-1683.

McMillan P, Korvatska E, Poorkaj P, Evstafjeva Z, Robinson L, Greenup L, Leverenz J, Schellenberg GD, D'Souza I (2008) Tau isoform regulation is region- and cell-specific in mouse brain. J Comp Neurol 511:788-803.

Melov S, Adlard PA, Morten K, Johnson F, Golden TR, Hinerfeld D, Schilling B, Mavros C, Masters CL, Volitakis I, Li QX, Laughton K, Hubbard A, Cherny RA, Gibson B, Bush AI (2007) Mitochondrial oxidative stress causes hyperphosphorylation of tau. PLoS One 2:e536.

Miller LM, Xiao H, Burd B, Horwitz SB, Angeletti RH, Verdier-Pinard P (2010) Methods in tubulin proteomics. Methods Cell Biol 95:105-126.

Moutier R, Tchang F, Caucheteux SM, Kanellopoulos-Langevin C (2003) Placental anomalies and fetal loss in mice, after administration of doxycycline in food for Tet-system activation. Transgenic Res 12:369-373.

Ohmi K, Kudo LC, Ryazantsev S, Zhao HZ, Karsten SL, Neufeld EF (2009) Sanfilippo syndrome type B, a lysosomal storage disease, is also a tauopathy. Proc Natl Acad Sci U S A 106:8332-8337.

Orr ME, Pitstick R, Canine B, Ashe KH, Carlson GA (2012) Genotypespecific differences between mouse CNS stem cell lines expressing frontotemporal dementia mutant or wild type human tau. PLoS One 7:e39328.

Planel E, Bretteville A, Liu L, Virag L, Du AL, Yu WH, Dickson DW, Whittington RA, Duff KE (2009) Acceleration and persistence of neurofibrillary pathology in a mouse model of tauopathy following anesthesia. FASEB J 23:2595-2604.

Polydoro M, Acker CM, Duff K, Castillo PE, Davies P (2009) Agedependent impairment of cognitive and synaptic function in the hTau mouse model of tau pathology. J Neurosci 29:10741-10749.

Poppek D, Keck S, Ermak G, Jung T, Stolzing A, Ullrich O, Davies KJ, Grune T (2006) Phosphorylation inhibits turnover of the tau protein by the proteasome: influence of RCAN1 and oxidative stress. Biochem J 400: 511-520.

Probst A, Götz J, Wiederhold KH, Tolnay M, Mistl C, Jaton AL, Hong M, Ishihara T, Lee VM, Trojanowski JQ, Jakes R, Crowther RA, Spillantini MG, Bürki K, Goedert M (2000) Axonopathy and amyotrophy in mice transgenic for human four-repeat tau protein. Acta Neuropathol 99:469 481.

Ren QG, Liao XM, Chen XQ, Liu GP, Wang JZ (2007) Effects of tau phosphorylation on proteasome activity. FEBS Lett 581:1521-1528.

Rodríguez-Martín T, Pooler AM, Lau DH, Mórotz GM, De Vos KJ, Gilley J, Coleman MP, Hanger DP (2016) Reduced number of axonal mitochondria and tau hypophosphorylation in mouse P301L tau knockin neurons. Neurobiol Dis 85:1-10.

Sakimura K, Kutsuwada T, Ito I, Manabe T, Takayama C, Kushiya E, Yagi T, Aizawa S, Inoue Y, Sugiyama H (1995) Reduced hippocampal LTP and spatial learning in mice lacking NMDA receptor epsilon 1 subunit. Nature 373:151-155.

Santacruz K, Lewis J, Spires T, Paulson J, Kotilinek L, Ingelsson M, Guimaraes A, DeTure M, Ramsden M, McGowan E, Forster C, Yue M, Orne J, Janus C, Mariash A, Kuskowski M, Hyman B, Hutton M, Ashe KH (2005) Tau suppression in a neurodegenerative mouse model improves memory function. Science 309:476-481.

Sarnat HB, Flores-Sarnat L (2015) Infantile tauopathies: hemimegalencephaly; tuberous sclerosis complex; focal cortical dysplasia 2; ganglioglioma. Brain Dev 37:553-562.

Sayas CL, Tortosa E, Bollati F, Ramírez-Ríos S, Arnal I, Avila J (2015) Tau regulates the localization and function of end binding proteins 1 and 3 in developing neuronal cells. J Neurochem 133:653-667.

Schoch KM, DeVos SL, Miller RL, Chun SJ, Norrbom M, Wozniak DF, Dawson HN, Bennett CF, Rigo F, Miller TM (2016) Increased 4R-tau induces pathological changes in a human-tau mouse model. Neuron 90: 941-947.

Semple BD, Blomgren K, Gimlin K, Ferriero DM, Noble-Haeusslein LJ (2013) Brain development in rodents and humans: identifying benchmarks of maturation and vulnerability to injury across species. Prog Neurobiol 106:1-16.

Serra HG, Duvick L, Zu T, Carlson K, Stevens S, Jorgensen N, Lysholm A, Burright E, Zoghbi HY, Clark HB, Andresen JM, Orr HT (2006) 
RORalpha-mediated Purkinje cell development determines disease severity in adult SCA1 mice. Cell 127:697-708.

Shea TB, Beermann ML (1994) Respective roles of neurofilaments, microtubules, MAP1B, and tau in neurite outgrowth and stabilization. Mol Biol Cell 5:863-875.

Spittaels K, Van den Haute C, Van Dorpe J, Bruynseels K, Vandezande K, Laenen I, Geerts H, Mercken M, Sciot R, Van Lommel A, Loos R, Van Leuven F (1999) Prominent axonopathy in the brain and spinal cord of transgenic mice overexpressing four-repeat human tau protein. Am J Pathol 155:2153-2165.

Su B, Wang X, Lee HG, Tabaton M, Perry G, Smith MA, Zhu X (2010) Chronic oxidative stress causes increased tau phosphorylation in M17 neuroblastoma cells. Neurosci Lett 468:267-271.

Teravskis PJ, Oxnard BR, Miller EC, Kemper L, Ashe KH, Liao D (2019) Phosphorylation in two discrete tau domains regulates a stepwise process leading to postsynaptic dysfunction. J Physiol. Advance online publication. Retrieved Jun 13, 2019. doi: 10.1113/JP277459.

Terwel D, Lasrado R, Snauwaert J, Vandeweert E, Van Haesendonck C, Borghgraef P, Van Leuven F (2005) Changed conformation of mutant tau-P301L underlies the moribund tauopathy, absent in progressive, nonlethal axonopathy of tau- $4 \mathrm{R} / 2 \mathrm{~N}$ transgenic mice. J Biol Chem 280: 3963-3973.

Vallee RB (1982) A taxol-dependent procedure for the isolation of microtubules and microtubule-associated proteins (MAPs). J Cell Biol 92:435-442.

Vossel KA, Xu JC, Fomenko V, Miyamoto T, Suberbielle E, Knox JA, Ho K, Kim DH, Yu GQ, Mucke L (2015) Tau reduction prevents abetainduced axonal transport deficits by blocking activation of GSK3beta. J Cell Biol 209:419-433.

Wang X, Zhao Y, Zhang X, Badie H, Zhou Y, Mu Y, Loo LS, Cai L, Thompson RC, Yang B, Chen Y, Johnson PF, Wu C, Bu G, Mobley WC, Zhang D, Gage FH, Ranscht B, Zhang YW, Lipton SA, et al. (2013) Loss of sorting nexin 27 contributes to excitatory synaptic dysfunction by modulating glutamate receptor recycling in Down's syndrome. Nat Med 19:473-480.

Waterham HR, Koster J, van Roermund CW, Mooyer PA, Wanders RJ, Leonard JV (2007) A lethal defect of mitochondrial and peroxisomal fission. N Engl J Med 356:1736-1741.

Weingarten MD, Lockwood AH, Hwo SY, Kirschner MW (1975) A protein factor essential for microtubule assembly. Proc Natl Acad Sci U S A 72:1858-1862.

Weitzner DS, Engler-Chiurazzi EB, Kotilinek LA, Ashe KH, Reed MN (2015) Morris Water Maze Test: optimization for mouse strain and testing environment. J Vis Exp 100:e52706.

Wiatr K, Szlachcic WJ, Trzeciak M, Figlerowicz M, Figiel M (2018) Huntington disease as a neurodevelopmental disorder and early signs of the disease in stem cells. Mol Neurobiol 55:3351-3371.

Wilson C, Muñoz-Palma E, González-Billault C (2018) From birth to death: a role for reactive oxygen species in neuronal development. Semin Cell Dev Biol 80:43-49.

Yamada K, Patel TK, Hochgräfe K, Mahan TE, Jiang H, Stewart FR, Mandelkow EM, Holtzman DM (2015) Analysis of in vivo turnover of tau in a mouse model of tauopathy. Mol Neurodegener 10:55.

Yoon Y, Krueger EW, Oswald BJ, McNiven MA (2003) The mitochondrial protein hFis1 regulates mitochondrial fission in mammalian cells through an interaction with the dynamin-like protein DLP1. Mol Cell Biol 23:5409-5420.

Yousefzadeh MJ, Schafer MJ, Noren Hooten N, Atkinson EJ, Evans MK, Baker DJ, Quarles EK, Robbins PD, Ladiges WC, LeBrasseur NK, Niedernhofer LJ (2018) Circulating levels of monocyte chemoattractant protein- 1 as a potential measure of biological age in mice and frailty in humans. Aging Cell 17:2.

Yu Y, Run X, Liang Z, Li Y, Liu F, Liu Y, Iqbal K, Grundke-Iqbal I, Gong CX (2009) Developmental regulation of tau phosphorylation, tau kinases, and tau phosphatases. J Neurochem 108:1480-1494. 